\title{
Regional representativity of AERONET observation sites during the biomass burning season in South America determined by correlation studies with MODIS Aerosol Optical Depth
}

\author{
Judith J. Hoelzemann, ${ }^{1}$ Karla M. Longo, ${ }^{1,2}$ Rafael M. Fonseca, ${ }^{1}$ Nilton M. E. do Rosário, ${ }^{3}$ \\ Hendrik Elbern, ${ }^{4,5}$ Saulo R. Freitas, ${ }^{1}$ and Carlos Pires ${ }^{6}$ \\ Received 5 May 2008; revised 6 April 2009; accepted 23 April 2009; published 3 July 2009.
}

[1] This paper presents an analysis of ground-based Aerosol Optical Depth (AOD) observations by the Aerosol Robotic Network (AERONET) in South America from 2001 to 2007 in comparison with the satellite AOD product of Moderate Resolution Imaging Spectroradiometer (MODIS), aboard TERRA and AQUA satellites. Data of 12 observation sites were used with primary interest in AERONET sites located in or downwind of areas with high biomass burning activity and with measurements available for the full time range. Fires cause the predominant carbonaceous aerosol emission signal during the dry season in South America and are therefore a special focus of this study. Interannual and seasonal behavior of the observed AOD at different sites were investigated, showing clear differences between purely fire and urban influenced sites. An intercomparison of AERONET and MODIS AOD annual correlations revealed that neither an interannual long-term trend may be observed nor that correlations differ significantly owing to different overpass times of TERRA and AQUA. Individual anisotropic representativity areas for each AERONET site were derived by correlating daily AOD of each site for all years with available individual MODIS AOD pixels gridded to $1^{\circ} \times 1^{\circ}$. Results showed that for many sites a good AOD correlation $\left(\mathrm{R}^{2}>0.5\right)$ persists for large, often strongly anisotropic, areas. The climatological areas of common regional aerosol regimes often extend over several hundreds of kilometers, sometimes far across national boundaries. As a practical application, these strongly inhomogeneous and anisotropic areas of influence are being implemented in the tropospheric aerosol data assimilation system of the Coupled Chemistry-Aerosol-Tracer Transport Model coupled to the Brazilian Regional Atmospheric Modeling System (CCATT-BRAMS) at the Brazilian National Institute for Space Research (INPE). This new information promises an improved exploitation of local site sampling and, thus, chemical weather forecast.

Citation: Hoelzemann, J. J., K. M. Longo, R. M. Fonseca, N. M. E. do Rosário, H. Elbern, S. R. Freitas, and C. Pires (2009), Regional representativity of AERONET observation sites during the biomass burning season in South America determined by correlation studies with MODIS Aerosol Optical Depth, J. Geophys. Res., 114, D13301, doi:10.1029/2008JD010369.

\section{Introduction}

[2] Aerosols are one of the largest uncertainties of climate forcing. A better understanding of current climate change is

\footnotetext{
${ }^{1}$ Center for Weather Forecast and Climate Studies, Brazilian National Institute for Space Research, Cachoeira Paulista, Brazil.

${ }^{2}$ Now at Spatial and Atmospheric Sciences Coordination, Brazilian National Institute for Space Research, São José dos Campos, Brazil.

${ }^{3}$ Institute of Astronomy, Geophysics and Atmospheric Science, University of São Paulo, São Paulo, Brazil.

${ }^{4}$ Rhenish Institute for Environmental Research, University of Cologne, Cologne, Germany.

${ }^{5}$ Also at Institute for Chemistry and Dynamics of the Geosphere 2, Research Center Juelich, Juelich, Germany.

${ }^{6}$ Satellites and Environmental Systems Division, Brazilian National Institute for Space Research, Cachoeira Paulista, Brazil.
}

Copyright 2009 by the American Geophysical Union. 0148-0227/09/2008JD010369\$09.00 still hampered by the prevalent insufficient knowledge on the impact of anthropogenic aerosols. Primarily fossil fuel combustion but also biomass burning modify the Earth's albedo [Forster et al., 2007] and redistribute the radiative energy within the atmosphere. Scattering and absorption interactions with solar radiation yield "direct effects" [e.g., Seinfeld and Pandis, 1998] while "indirect effects" result from influences on cloud microphysics: potentially impacting cloud lifetime, precipitation and the hydrological cycle [e.g., Twomey, 1977; Albrecht, 1989; Kaufman, 1995; Lohmann and Feichter, 2005].

[3] The geographical, seasonal and interannual distribution, chemical composition, and properties of aerosols are in general highly variable. This is particularly true for smoke particles in the atmosphere over South America that are released every year from biomass burning activities and represent the major aerosol source during the burning 
season. In the vicinity of megacities, urban industrial emissions may be predominant; however, on the continental scale sources are mainly composed of carbonaceous aerosol and trace gas emissions from deforestation and savanna maintenance fires. Hundreds of thousands of vegetation fires, primarily in cerrado and forest ecosystems, emit vast amounts of aerosol particles into the atmosphere during the burning season [Setzer and Pereira, 1991; Artaxo et al., 2005]. These fires occur mostly in the Amazonian region and central Brazil, however, by atmospheric transport, their emissions produce a spatial smoke distribution over a large area of about 3-5 million $\mathrm{km}^{2}$ [Artaxo et al., 2006]. This is considerably higher than the area where the fires sources are concentrated [Freitas et al., 2005, 2007a]. Aerosol effects by fires may go far beyond the local scale and significantly affect the hydrological cycle on a regional scale, including consequences in the redistribution pattern of tropical planetary energy to medium and high latitudes. If meteorological conditions are favorable, the smoke plumes can be injected into altitudes above the planetary boundary layer [e.g., Andreae et al., 2001; Freitas et al., 2007b]. From there they can even be transported over thousands of kilometers on an intercontinental scale. Smoke aerosols act as climate forcing "agent" [e.g., Kaufman and Fraser, 1997; Christopher et al., 2000], by heating the aerosol atmospheric layers and thereby reducing the available solar energy reaching the surface, and change the chemical air composition. On short time scales the tropospheric smoke aerosol load often leads to heavy pollution and thus, to health effects on the population.

[4] For some years, operational chemical weather forecasts are produced in many countries to inform the population on critical levels of aerosol and trace gas concentrations in the air. Mostly, these efforts are in conjunction with research and development of chemical weather prediction models and case studies over longer periods to understand and improve the underlying chemistry, vertical and horizontal transport processes, emission sources, trends, and variabilities of tropospheric chemical composition (e.g., the CCATTBRAMS model of INPE in Brazil (http://meioambiente. cptec.inpe.br/), the EURAD model at RIU at the University of Colgogne, Germany (http://www.eurad.uni-koeln.de), or WRF-CHEM at NOAA (http://www-frd.fsl.noaa.gov/aq/ wrf/)). However, there are several uncertainties inherent in these atmospheric models due to unknown or not yet fully understood processes.

[5] In the last decades, satellite aerosol products have become available to help reduce these uncertainties on the tropospheric aerosol load (e.g., Moderate Resolution Imaging Spectroradiometer (MODIS) aboard NASA's TERRA and AQUA satellites, MODIS-like products from Visible Infrared Imaging Radiometer Suite (VIIRS), Sea-viewing Wide Field-of-view Sensor (SeaWiFS), Polar Operational Environmental Satellite (POES NOAA/AVHRR), Total Ozone Mapping Spectrometer (TOMS), Cloud-Aerosol Lidar and Infrared Pathfinder Satellite Observation (CALIPSO) with vertical resolution, or the European Meteosat Second Generation-Spinning Enhanced Visible and Infrared Imager (MSG-SEVIRI), and other satellite platforms as Global Ozone Monitoring Experiment (GOME), Along-Track Scanning Radiometer (ATSR) on board of European Remote Sensing satellite 2 (ERS2), Scanning Imaging Absorption
Spectrometer for Atmospheric Chartography (SCIAMACHY), and Advanced ATSR (AATSR) on Environmental Satellite (ENVISAT)). Satellite observations may detect unknown global or regional patterns, daily variations and seasonalities that are not reproduced by models. These data may be used in atmospheric model evaluations by intercomparison, or directly improve model results by using data assimilation techniques, if retrieval capability in comparison to more accurate aerosol property by ground-based remote sensing has been demonstrated. Satellite observations are expected to provide reference to global, regional, seasonal and even diurnal patterns. These data rely on assumptions of essential aerosol and environmental properties, which cannot be measured by remote sensing techniques. Thus, aerosol retrievals may insert considerable uncertainties in the final aerosol product, especially over land with its more heterogeneous surface (albedo) properties and troposphere. The geographically sparse ground-based monitoring sites that exist, although yielding small quantities of data compared to satellites, play therefore an important role to validate satellite data and models. For an extended spatial high-quality observational data coverage, synergetic products of remote sensing from ground and space would be desirable.

[6] Successful air pollution modeling with the aim to reconstruct or predict a realistic chemical state of the atmosphere requires good information on sources. The atmospheric numerical model Coupled Chemistry-AerosolTracer Transport model coupled to the Brazilian developments on the Regional Atmospheric Modeling System (CCATT-BRAMS) [Walko et al., 2000; Freitas et al., 2005, 2007a] used at CPTEC/INPE makes use of the Brazilian Biomass Burning Emission Model (3BEM) to provide daily fire emission estimates [Longo et al., 2007]. Although making best use of all available data, such as three different fire satellite products, emission factors, burning efficiencies, and biomass loads from literature, considerable uncertainties prevail in absolute emission fluxes.

[7] One solution to correct these uncertainties may be the assimilation of aerosol satellite data into CCATT-BRAMS. Before that, it is of utmost importance to assess the skill of potential assimilation data to gain knowledge on improvements that may be expected by assimilation. For assimilation purposes, focusing on South America, tropospheric columns of satellite Aerosol Optical Depth derived from MODIS, collection 5 (C5), and ground-based Aerosol Optical Depth (AOD) observations from the Aerosol Robotic Network (AERONET) are available. MODIS satellite data exist on a daily, near-real-time operational basis, starting in the year 2000 for TERRA satellite and 2002 for the MODIS instrument aboard AQUA. Existing studies that have evaluated and intercompared these data mostly rely on older MODIS collection 4 (C4) data, investigate only 12 years or only one site, or focus on other continents [e.g., Chu et al., 2003; Hauser et al., 2005; Tripathi et al., 2005; Kovacs, 2006; Li et al., 2007; Misra et al., 2008; de Almeida Castanho et al., 2008].

[8] In this paper we present the first long-term study on MODIS C5 AOD and AERONET AOD intercomparison for South America covering the years 2001-2007. The aim of this study is to shed more light on interannual and intraseasonal variability, if particular trends in correlations of 
these data can be observed, and how spatial correlations may extend local information in aerosol data assimilation.

[9] On one hand the MODIS AOD product yields some caveats over South America and a number of other regions around the globe, related to the application of a global algorithm. This algorithm assumes general, averaged, global aerosol models [Remer et al., 2005]. However, absorption and optical properties of smoke and urban/industrial aerosols display significant variability on local or regional scales [Dubovik et al., 2002]. Therefore, AOD data users are required to exploit the available ground-based measurements as best as possible in addition to the satellite data. On the other hand, ground-based data may strongly profit from information achieved by the use of satellite data: correlations may be used to define radii and areas of influence for each local station to spread this sparse and valuable information spatially around each site based on a sound statistic approach.

[10] This paper is organized as follows: we describe the observational data used in this study in section 2 . Section 3 exposes the methodology used for the correlation studies of AOD from satellite and local measurement sites and establishes an isotropic approach to determine radii of influence for each AERONET observation site. Since in reality high correlations may favor specific geographical directions owing to local orography, preferential wind directions, etc., section 4 introduces a more sophisticated methodology to derive anisotropic areas of influence for each AERONET site. In section 5 we present AOD time series and histograms and present and discuss results from the isotropic radii of influence and the derived anisotropic areas. Final conclusions are drawn in section 6 .

\section{Data}

\subsection{AERONET Data Description}

[11] The AERONET program is a federation of groundbased remote sensing aerosol networks established by NASA and LOA-PHOTONS (CNRS), expanded by collaborators. The program provides a long-term, continuous, and readily accessible public domain database of aerosol optical, microphysical and radiative properties (http://aeronet.gsfc. nasa.gov). AERONET provides globally distributed observations of spectral columnar AOD measured with Cimel Sun Photometers [Holben et al., 1998].

[12] In this study we used cloud-screened level 2.0 AOD at $500 \mathrm{~nm}\left(\tau_{500}\right)$ processed with the version 2.0 algorithm, interpolated to $550 \mathrm{~nm}$ using the Angstrom coefficient $(\alpha)$ for 440-675 nm (A. L. Correia and C. A. Pires Junior, Validation of aerosol optical depth retrievals by remote sensing over Brazil and South America using MODIS, paper presented at Congresso Brasileiro de Meteorologia, 2006, Anais do Congresso Brasileiro de Meteorologia, Florianpolis, 2006):

$$
\tau_{550 \mathrm{~nm}}=\tau_{500 \mathrm{~nm}} / \exp \left[-\alpha \ln \left(\lambda_{500} / \lambda_{550}\right)\right]
$$

This interpolation guarantees comparability to the MODIS AOD at $550 \mathrm{~nm}$. Measurements of 12 South American sites were used in (Figure 1) with primary focus on sites with availability of the whole time series from 2001-2007 to ensure statistical significance. Table 1 provides information on exact location and altitude of these 12 sites. Sites that were the main focus of this study with high undisturbed AOD at $550 \mathrm{~nm}$ (henceforth simply AOD) signals during fire season and with a full record of measurements from 2001 to 2007 are bold. Urban sites located in large cities with a near to full record of measurements are italic. The biomass burning season mean AOD calculated with all available data from August to October 2001-2007, separately at TERRA and AQUA over pass times (denoted "T" and "A," respectively), show a much higher AOD mean for AERONET sites located close to the fire emission sources than for the urban observation sites. Sites with high fire emission influence frequently yield maximum AOD values of up to three, while urban sites mostly remain below one. The standard deviations indicate a strong AOD variation for all sites during the burning season.

\subsection{MODIS Data Description}

\subsubsection{MODIS Level 2 Aerosol Optical Depth}

[13] The MODIS instrument aboard TERRA and AQUA satellites, that are part of the NASA-centered international Earth Observing System (EOS), delivers global retrievals of columnar AOD at $550 \mathrm{~nm}$ since the year 2000 (TERRA and 2002 (AQUA)). This study uses the Atmosphere Level 2, Collection 5 (C5) product (MOD04_02 and MYD04_02) from 2001 to 2007, described in the MODIS ATBD-MOD-02 document by Remer et al. [2006] (available at http://modis. gsfc.nasa.gov/data/atbd/atmos_atbd.php) and Levy et al. [2007a, 2007b]. Data are available from the MODIS Adaptive Processing System (MODAPS) Services Web site (https://modaps. nascom.nasa.gov:8499/). The data are delivered in Hierarchical Data Format (HDF) for individual tiles with a resolution of $10 \mathrm{~km} \times 10 \mathrm{~km}$ (at nadir) of each pixel. Overpass times of TERRA and AQUA over South America occur between 1200 and 1500 UTC, and from 1600 to 1900 UTC, respectively. Figure 2 shows an example of a typical AOD $550 \mathrm{~nm}$ scene monitored by TERRA during high biomass burning season over South America on 3 September 2005. High AOD values can be observed over a large area with abundant fire activity in central Brazil and a hint of emission outflow by transport in southeastern direction can be seen.

\subsubsection{MODIS Level 3 Gridded AOD From MOVAS}

[14] Gridded daily MODIS Level 3 collection 5 data (MOD08 D3.005 and MYD08 D3.005) separated for TERRA ands AQUA at a spatial resolution of $1^{\circ} \times 1^{\circ}$ is available from the Giovanni MODIS Online Visualization and Analysis System (MOVAS) located at http://daac.gsfc. nasa.gov/techlab/giovanni. These MODIS data are used in the approach presented in section 4 for the years 2001 to 2007, where gridded data are required to provide full spatial coverage and computational efficiency.

\section{Methodology of MODIS and AERONET AOD Intercomparison in South America}

[15] Daily hourly means of AERONET AOD from 20012007 during the biomass burning season (August to October) were compared at corresponding TERRA/AQUA MODIS overpass times. One MODIS pixel is equivalent to an area of about $10 \times 10 \mathrm{~km}$ (at nadir). MODIS AOD was spatially averaged to be compared with AERONET 


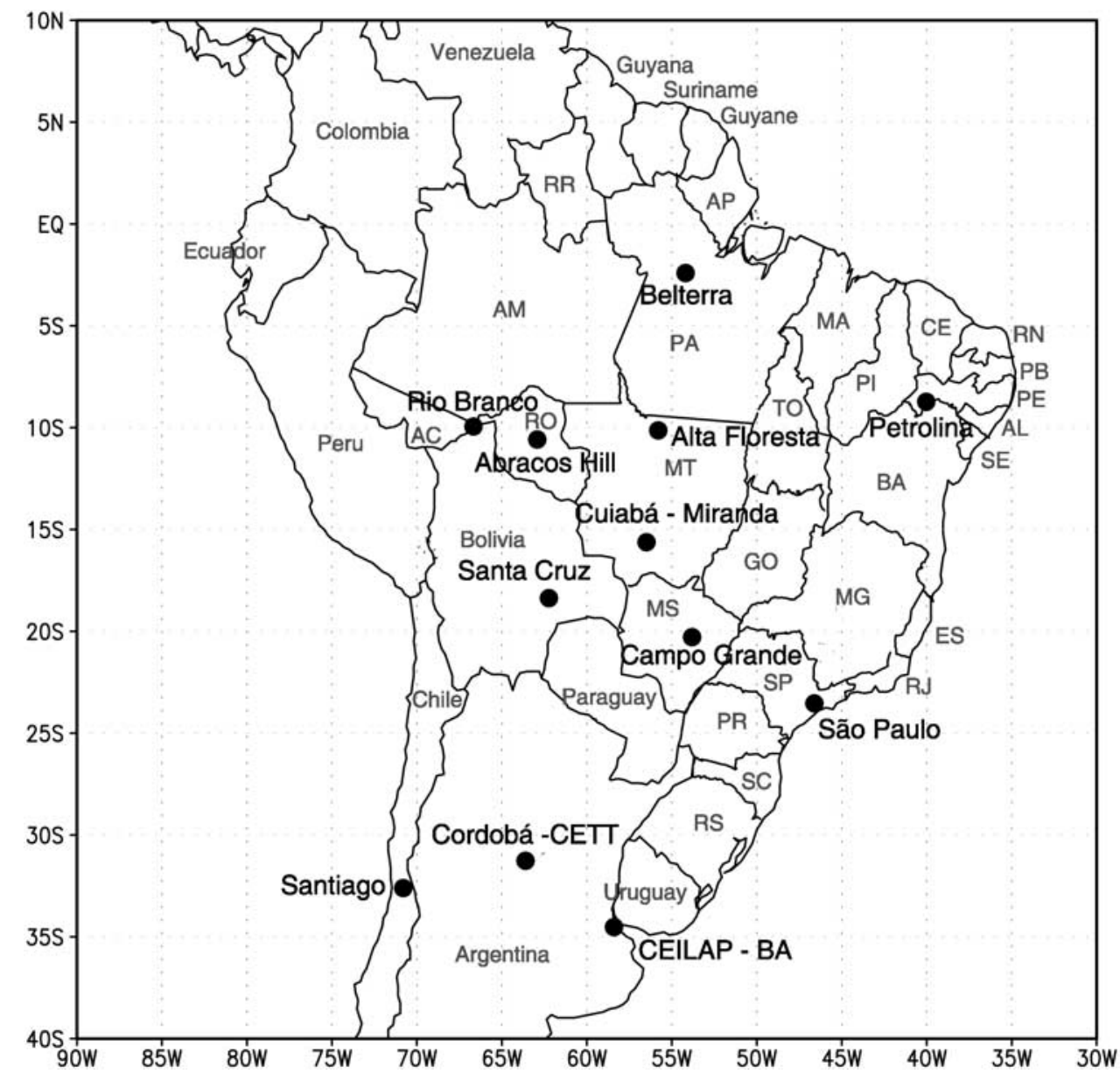

Figure 1. Location of AERONET sites in South America with AOD measurements during the period $2001-2007$.

ground-based AOD taking into account different radii around each AERONET site: a spatial mean was calculated for 1, 9, 25, and 225 MODIS pixels, respectively. This corresponds approximately to areas of $10 \times 10 \mathrm{~km}, 30 \times$ $30 \mathrm{~km}, 50 \times 50 \mathrm{~km}$, and $150 \times 150 \mathrm{~km}$ around each site. AERONET AOD values were calculated as daily and hourly means, that is $30 \mathrm{~min}$ before MODIS overpass and $30 \mathrm{~min}$ after MODIS overpass.

[16] Fire activity during the burning season in Brazil shows a distinct peak during the afternoon [Prins et al., 1998] with a maximum around $\sim 1500$ local time. This is close to AQUA overpass, whereas TERRA crosses the Southern American continent during the morning. AQUA and TERRA data were processed separately to investigate possible different smoke pollution scenarios over the continent at the satellite's different overpass times, according to the diurnal evolution of fire activity. Correlations were calculated for all AERONET stations with available data for at least 3 years over the period 2001-2007 (see Table 1). As expected correlation is higher for AERONET hourly mean AOD than for diurnal mean for all MODIS samples and were therefore used throughout this study.

[17] The main objectives were to identify systematic differences in correlations of TERRA and AQUA AOD data, explore if a trend exists in the data within the interannual variability, and to investigate whether the correlation studies with the spatial means of MODIS data around each AERONET site may serve to establish radii of influence as additional background information for tropospheric aerosol data assimilation purposes. As local observation sites are rare and sparsely located with several hundred of kilometers distance, it is important to make optimal use of available information at the sites. Introducing validated radii of influence (or decorrelation lengths) a region around each AERONET site can be determined by statistical means that may profit from the retrieved AOD at the site during assimilation.

\section{Methodology of Regional Anisotropic Representativity Studies}

[18] Typically, in data assimilation the validity of a measurement is taken to be circularly decreasing with distance from the site. Isotropy and the resulting radius of influence is held fixed all over the analysis domain. However, following terrain formation, with land use and fire event distribution, these simplifying assumptions are violated in most cases. Efficient use of available observations strives to exploit the information content in directions with extended validity (anisotropy). As for each observation 
Table 1. Description of AERONET Sites Used in This Study ${ }^{a}$

\begin{tabular}{|c|c|c|c|c|c|c|}
\hline AERONET Site & Longitude & Latitude & Altitude (m) & Data Availability & Aug-Oct Mean AOD T/A & Maximum AOD \\
\hline Abracos Hill & -62.358 & -10.760 & 200 & $2001-2005$ & $\begin{array}{l}\text { T } 0.62 \pm 0.44 \\
\text { A } 0.83 \pm 0.45\end{array}$ & $\begin{array}{l}2.04 \\
1.98\end{array}$ \\
\hline Alta Floresta & $-\mathbf{5 6 . 0 1 7}$ & -9.917 & 175 & $2001-2007$ & $\begin{aligned} \text { T } 0.81 & \pm \mathbf{0 . 7 3} \\
\text { A } 0.81 & \pm \mathbf{0 . 7 0}\end{aligned}$ & $\begin{array}{l}4.04 \\
3.60\end{array}$ \\
\hline Belterra & -54.952 & -2.648 & 70 & $2001-2003$ & $\begin{aligned} & \text { T } 0.23 \pm 0.13 \\
& \text { А } 0.23 \pm 0.15\end{aligned}$ & $\begin{array}{l}0.53 \\
0.51\end{array}$ \\
\hline Campo Grande SONDA & -54.538 & -20.438 & 677 & $2004-2005$ & $\begin{array}{l}\text { T } 0.39 \pm 0.42 \\
\text { A } 0.37 \pm 0.36\end{array}$ & $\begin{array}{l}1.79 \\
1.58\end{array}$ \\
\hline CEILAP-BA & -58.500 & -34.567 & 10 & $2001-2006$ & $\begin{array}{l}T 0.12 \pm 0.12 \\
A 0.12 \pm 0.10\end{array}$ & $\begin{array}{l}0.85 \\
0.58\end{array}$ \\
\hline Cordoba-CETT & -64.466 & -31.524 & 730 & $2001-2007$ & $\begin{array}{l}T 0.11 \pm 0.10 \\
A 0.15 \pm 0.15\end{array}$ & $\begin{array}{l}0.50 \\
1.20\end{array}$ \\
\hline Cuiabá-Miranda & -56.021 & -15.730 & 210 & $2001-2007$ & $\begin{aligned} \text { T } 0.55 & \pm 0.49 \\
\text { A } 0.43 & \pm 0.35\end{aligned}$ & $\begin{array}{l}2.50 \\
1.52\end{array}$ \\
\hline Petrolina-SONDA & -40.500 & -9.383 & 370 & 2004,2007 & $\begin{array}{l}\text { T } 0.08 \pm 0.04 \\
\text { A } 0.09 \pm 0.05\end{array}$ & $\begin{array}{l}0.17 \\
0.23\end{array}$ \\
\hline Rio Branco & -67.869 & -9.957 & 212 & $2001-2007$ & $\begin{aligned} \text { T } 0.54 & \pm 0.43 \\
\text { A } 0.61 & \pm 0.45\end{aligned}$ & $\begin{array}{l}2.30 \\
1.99\end{array}$ \\
\hline Santa Cruz & -63.178 & -17.802 & 442 & $2002,2003,2005$ & $\begin{array}{l}\text { T } 0.34 \pm 0.28 \\
\text { A } 0.43 \pm 0.38\end{array}$ & $\begin{array}{l}1.17 \\
1.72\end{array}$ \\
\hline Santiago & -70.717 & -33.490 & 510 & $2001-2002$ & $\begin{array}{l}\text { T } 0.18 \pm 0.10 \\
\text { А } 0.12 \pm 0.06\end{array}$ & $\begin{array}{l}0.40 \\
0.23\end{array}$ \\
\hline São Paulo & -46.735 & -23.561 & 865 & $2001-2006$ & $\begin{array}{l}T 0.27 \pm 0.19 \\
A 0.28 \pm 0.19\end{array}$ & $\begin{array}{l}1.40 \\
0.23\end{array}$ \\
\hline
\end{tabular}

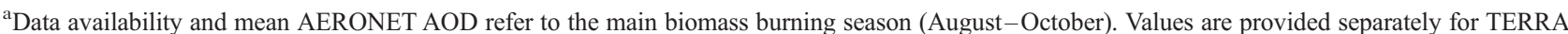
(T) and AQUA (A) overpass time with standard deviation. The "maximum AOD" column provides the maximum value found for observed AERONET AOD during the whole period. Sites that were the main focus of this study with high undisturbed AOD at $550 \mathrm{~nm}$ signals during fire season and with a full record of measurements from 2001 to 2007 are in bold. Urban sites located in large cities with a near to full record of measurements are in italic.

site this assessment is performed individually, an inhomogeneous, terrain adapted methodology can be obtained.

[19] With the advent of satellite data, the databases are significantly extended and this richness can be used to identify detailed areas of representativity. From a technical viewpoint, in data assimilation parlance, anisotropic areas of influence or decorrelation lengths can be designated. The anisotropic definition of a radius of influence is more appropriate as it may better represent natural conditions of some similarity around an observation site. Moreover, a term like "area of influence" is better suited to denote prevailing similarity conditions (see Elbern et al. [2007] for a practical way to handle related covariance matrices in data assimilation). As a consequence, in addition to the isotropic approach for introduction of radii of influence for each AERONET site in section 3, an anisotropic statistical approach was developed taking into regard climatological AOD information.

[20] The method chosen for creating anisotropic radii of influence for each of the 12 South American AERONET sites relies on a correlation study of AERONET and $1^{\circ} \times 1^{\circ}$ gridded MODIS AOD data (MOVAS, see section 2.2.2) for the burning seasons from 2001 to 2007 (i.e., 1 August to 31 October). For the present approach the gridded MODIS data were preferred to the original ungridded $10 \mathrm{~km} \times 10 \mathrm{~km}$ pixels (see section 2.2.1) to guarantee full spatial coverage and efficient computability, which is a prerequisite for its application in a data assimilation code. Taking the latter instead of the original $10 \mathrm{~km} \times 10 \mathrm{~km}$ resolution also results in smoothed correlation fields intentionally desired here, suppressing spurious local correlations.

[21] A Pearson correlation map was calculated on the basis of daily AOD data pairs of each AERONET site with regard to all MOVAS AOD grid boxes during the burning season, i.e., all days in August-October 2001-2007. The correlation at a grid box with indices $\mathrm{i}$ and $\mathrm{j}$ for a specific site is calculated as follows:

$$
\begin{aligned}
\operatorname{Corr}_{\text {site }}(\mathrm{i}, \mathrm{j})= & \operatorname{Corr}\left[\tau_{\text {aero }}(\mathrm{x}, \mathrm{y}, t), \tau_{\text {movas }}(\mathrm{i}, \mathrm{j}, t)\right], \\
& \forall t \in[1 / 8 / 2001,31 / 10 / 2007]
\end{aligned}
$$

where $\tau_{\text {aero }}, \tau_{\text {movas }}$ are the respective AOD's, $\mathrm{x}, \mathrm{y}$ are the coordinates of a specific AERONET site, $\mathrm{i}, \mathrm{j}$, are the indices of all $1^{\circ} \times 1^{\circ}$ gridded MOVAS grid points, and $t$ is the time. These maps are presented in Figure 10 and shall be discussed in section 5.3.

[22] To gain an overview of extent and limits of influence of each AERONET site the areas of influence needed to be aggregated into a single consistent map. In practice the gained climatological information on regional correlation of each AERONET site can be applied for formulation of the background error covariance matrix. Thus, an array was computed by identifying the site with the highest correlation for each $1^{\circ} \times 1^{\circ}$ grid box (Figure 11). This part of the study was also distinguished between TERRA and AQUA AOD products to investigate a possible different behavior due to differing overpass times. In this final dominant influence map, only values of $\mathrm{R}^{2}>0.5$ were considered as appropriate to define a sustained area of influence around each site. Favoring a conservative approach, spurious pixels that identify disconnected and often remote spots of high AERONET/MODIS correlations of a site were also eliminated from the map.

\section{Results and Discussion}

\subsection{Interannual and Seasonal AOD Variation}

[23] Figures 3-5 present daily hourly mean AOD $550 \mathrm{~nm}$ records by AERONET (in red, taken at MODIS over pass time), and MODIS (black) aboard TERRA and AQUA from 


\section{AOD 550nm MODIS/TERRA 3 SEP 2005}
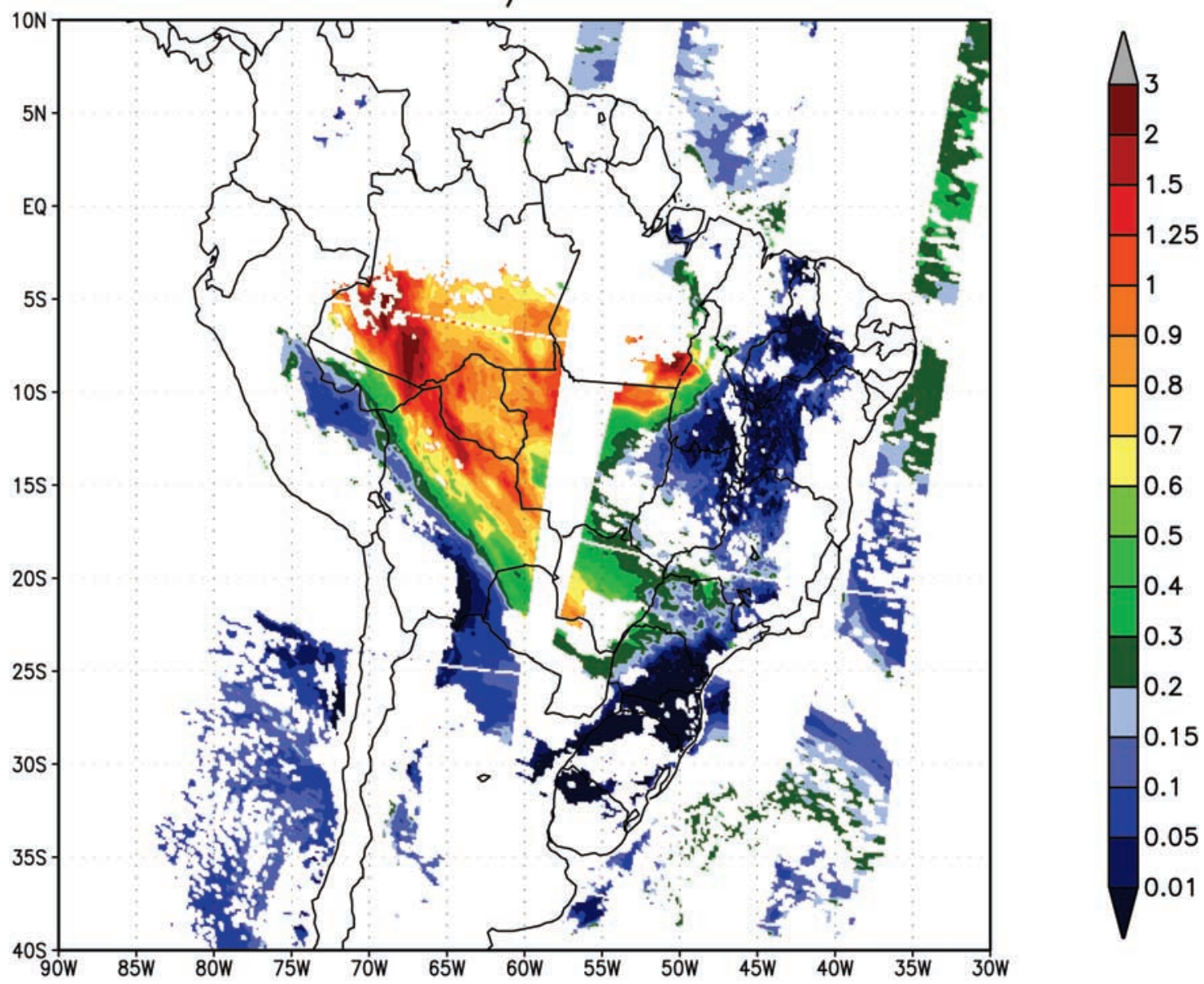

Figure 2. Typical MODIS/TERRA AOD scene at $550 \mathrm{~nm}$ over South America on 3 September 2005.

2001-2007, located over AERONET observation sites. Only AERONET/MODIS data pairs are depicted. Data from TERRA (Figure 3) yield the longest time series starting in 2001. Figure 3 shows the four AERONET observation sites with records over the observed period and predominant signals from biomass burning emissions (see also Table 1): Abracos Hill, Rio Branco, Cuiabá-Miranda, and Alta Floresta, all located in Brazil in areas with high fire activity. The AOD regularly peaks during the burning season from August to October for all measurement sites in Figure 3. Highest AOD was observed for the year 2007 at all sites. Years 2001, 2003, and 2004 were years with lower AOD signal, due to a lesser occurrence of fires. Generally, MODIS AOD reaches a higher maximum AOD at these sites than measurements from AERONET, while it underestimates low AOD values compared to local observations. Li et al. [2007] conducted a study in China comparing AOD of the MODIS C4 and C5 algorithm with ground-based Sun photometer observations and attributed the discrepancies to the choice of aerosol type in the algorithm's aerosol model. In the MODIS C5 data suite, the aerosol models are modified according to AERONET observations. These are possibly taken under conditions with very different emission scenarios and thus induce regional biases into the data when applying it to regions with very different situations, such as China [Li et al., 2007], or Brazil. Kinne et al. [2003] suggest that the MODIS AOD high bias may be explained to the fact that AERONET sites only measure AOD under cloud-free conditions, whereas MODIS is able to detect aerosols under more cloudy patterns, often associated with higher AOD levels. However, it may also occur that subpixel clouds are tagged as aerosol, which would erroneously raise the retrieved aerosol AOD. Further studies report MODIS AOD overestimates such as Ichoku et al. [2005], Abdou et al. [2005], and Hauser et al. [2005].

[24] Figure 4 presents the same site's records for MODIS/ AQUA, launched in May 2002, with the respective AERONET AOD hourly mean taken at the satellite's overpass time in the afternoon. Visibly, AQUA observations are less dense than for TERRA for all years and observation sites, which can be attributed to general higher cloud coverage in the afternoon (AQUA) than during the morning (TERRA) [Koren et al., 2004].

[25] Other AERONET sites influenced by South American biomass burning activity are Campo Grande in the Brazilian state Mato Grosso do Sul and Santa Cruz in Bolivia (not shown). Despite their vicinity to urban infrastructure and thus exposure to industrial and vehicular emission sources, these sites yield a clear and significant signal of elevated AOD owing to transported and local biomass burning emissions during the burning season. 

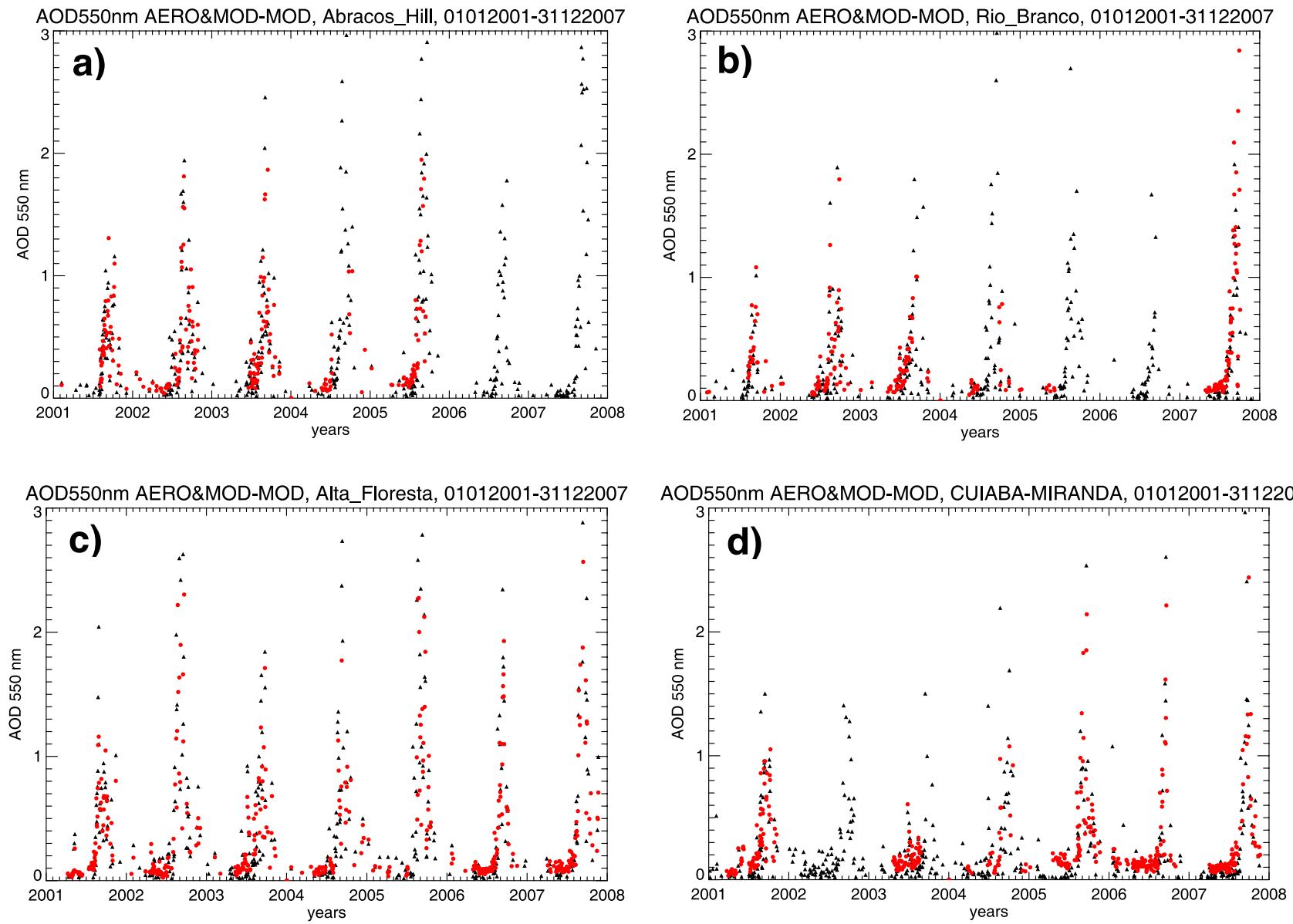

Figure 3. AOD $550 \mathrm{~nm}$ time series (2001-2007) of MODIS/TERRA (black) and AERONET (red) at sites located in biomass burning influenced regions: (a) Abracos Hill, (b) Rio Branco, (c) Alta Floresta, and (d) Cuiabá Miranda. AERONET values are hourly means centered at TERRA overpass time.

[26] An example of AERONET sites with clearly urban properties is shown in Figure 5. The sites in São Paulo and in Buenos Aires (CEILAP-BA) show a more diffuse AOD pattern than those sites exposed mainly to biomass burning emissions. São Paulo however, also yields an elevated AOD signal during austral winter. These maxima are related to lower precipitation rates and the typical more stable Planetary Boundary Layer (PBL) during this period, nevertheless, most extreme events are indeed associated with biomass burning emission transport from deforestation and maintenance fires in other Brazilian states such as Mato Grosso do Sul, Mato Grosso, Rondônia, and Acre. Also inside the state of São Paulo carbonaceous aerosols may be emitted from agricultural motivated fires and fires related to sugarcane harvesting during the dry season from June to October. In this season atmospheric blocking events may occur, leading to stagnating weather conditions that favor an accumulation of aerosols over São Paulo, and thus enhanced tropospheric AOD.

[27] In Buenos Aires the impact from fires on the tropospheric aerosol load is less visible however, it is known that the fire plumes from central Brazil are often transported over Argentina [Freitas et al., 2007b]. Agricultural fires in the floodplain of the Paraná River northwest from Buenos Aires, may carry intense fire plumes over the city, such as recently documented by B. Faries and E. Raszewski
(Smoke Cloaks Buenos Aires City as Farmers Burn Fields, Bloomberg. com, 17 April 2008) and visible on MODIS fire product images (http://earthobservatory.nasa.gov/Natural Hazards/) on 17 April 2008. Elevated AOD measurements, as shown in Figure 5 may thus be either related to largescale fire emission transport from central Brazil, or from regional transport from national territory.

[28] The other urban AERONET sites in South America with measurements from 2001 to 2007 are Córdoba-CETT, also in Argentina, and Santiago in Chile (not shown). For the latter only a very short period of AOD data was measured by AERONET (parts of 2001-2002) and MODIS AOD yields a signal that cannot yet be fully explained but seems to be related to an inappropriate assumption on vertical aerosol distributions and treatment of cirrus clouds (A. Oyanadel et al., Aerosol loading over Santiago de Chile: A comparison between satellite and in situ measurements, paper presented at 8 th International Conference on Southern Hemisphere Meteorology and Oceanography (8 ICSHMO), National Institute for Space Research, Foz do Iguaçu, Brazil, 24-28 Apr., 2006; L. Gallardo, personal communication, 2008). Córdoba however, shows a seasonal behavior with elevated AOD during the South American burning season that may be associated to the transport of fire emissions from the north/northwest, as well as local fire activity. Generally, AOD at urban sites has systematically 

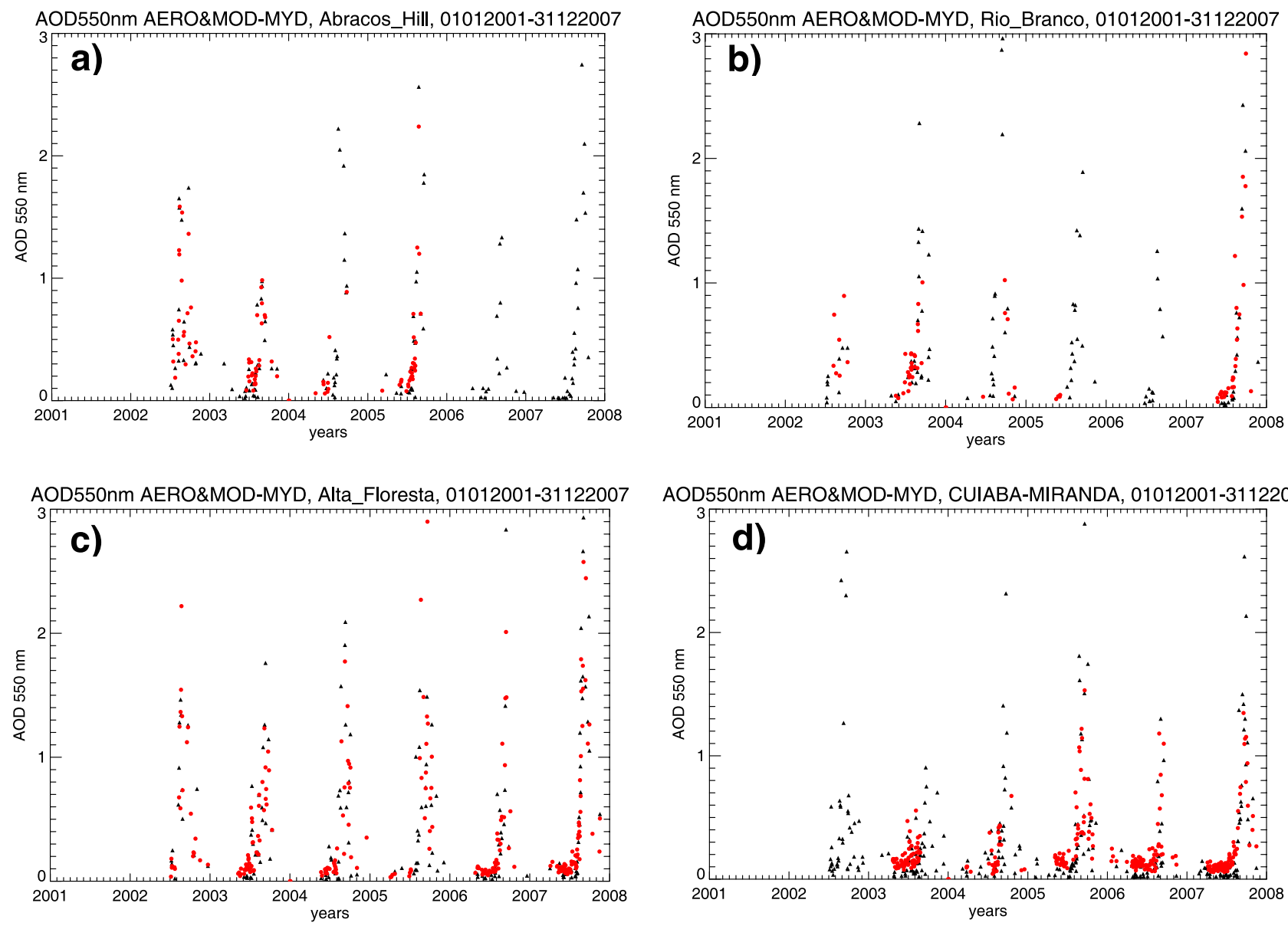

Figure 4. AOD $550 \mathrm{~nm}$ time series (2001-2007) of MODIS/AQUA (black) and AERONET (red) at sites located in biomass burning influenced regions: (a) Abracos Hill, (b) Rio Branco, (c) Alta Floresta, and (d) Cuiabá Miranda. AERONET values are hourly means centered at AQUA overpass time.

lower maxima than those sites located in or under impact of fire active regions and seldom exceed an AOD of 1.

[29] Finally, the AERONET site Belterra, located in the north of Brazil, a rural site and remote from fire activity, shows a burning season related AOD variability due to

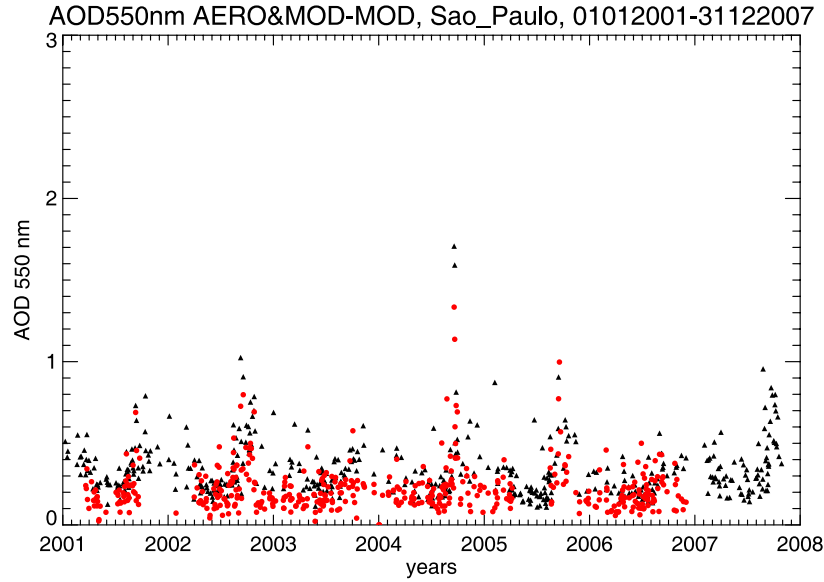

transport of fire emissions with AOD regularly below 0.6. The AOD record of Petrolina, further to the northeast, was investigated for similar transport features. Only few AERONET measurements were carried out at this site, according to MODIS a seasonal variability seems to exist with a

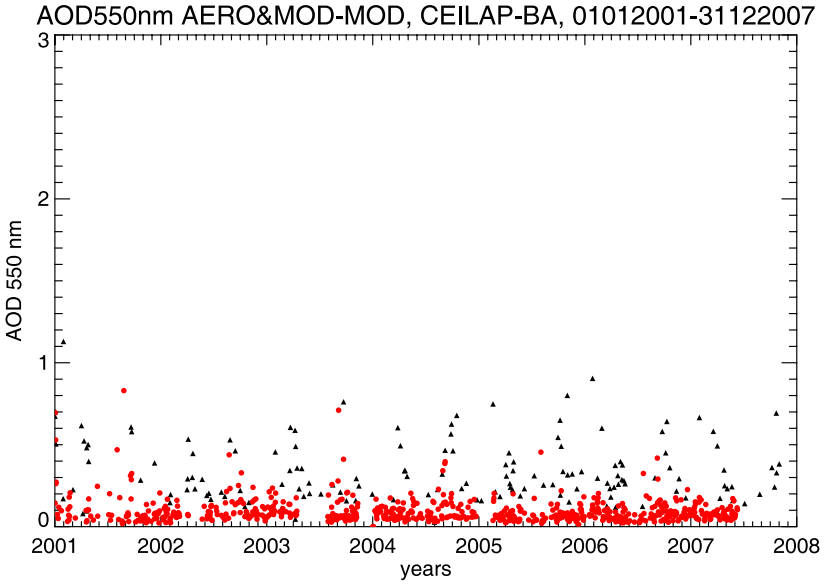

Figure 5. AOD $550 \mathrm{~nm}$ time series (2001-2007) of MODIS/TERRA (black) and AERONET (red) at sites located in urban centers: (left) São Paulo and (right) Buenos Aires (CEILAP-BA). AERONET values are hourly means centered at TERRA overpass time. 

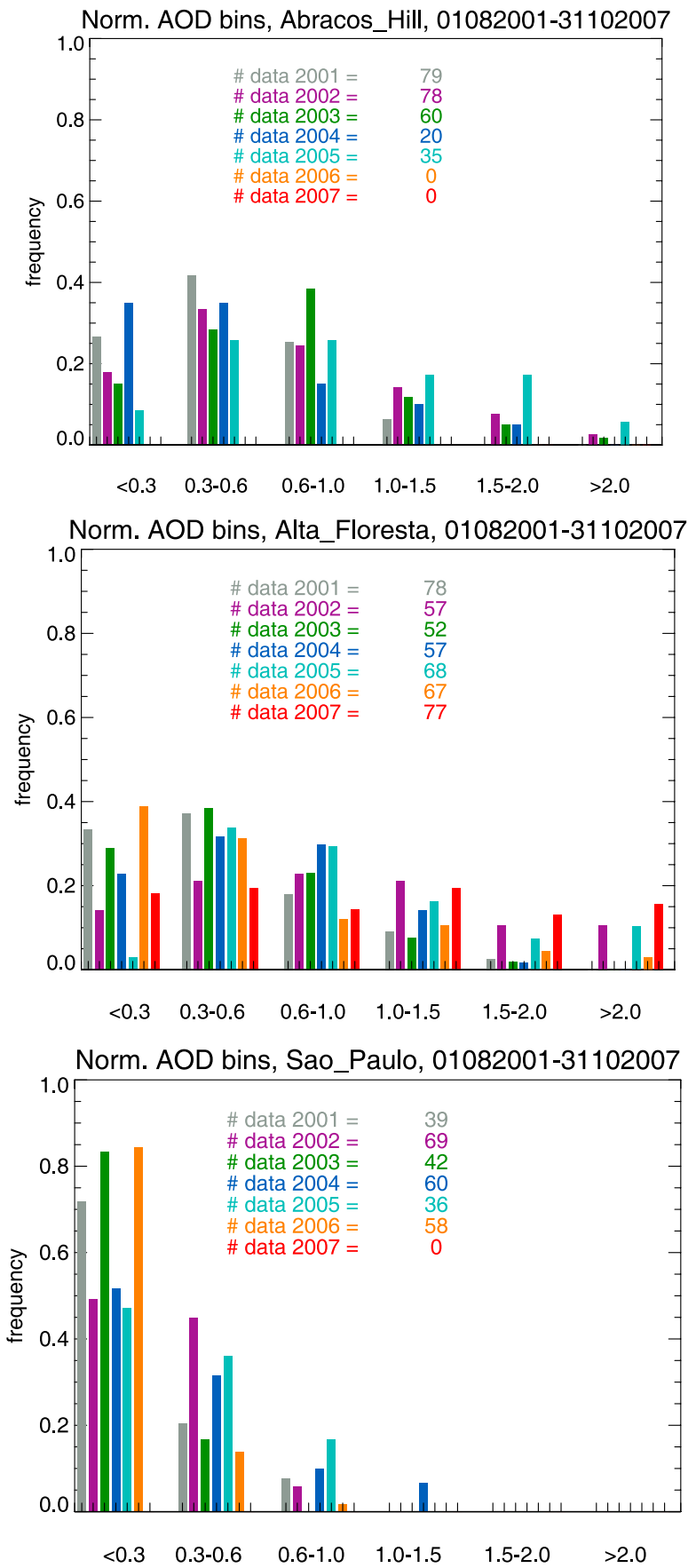

Norm. AOD bins, Rio_Branco, 01082001-31102007
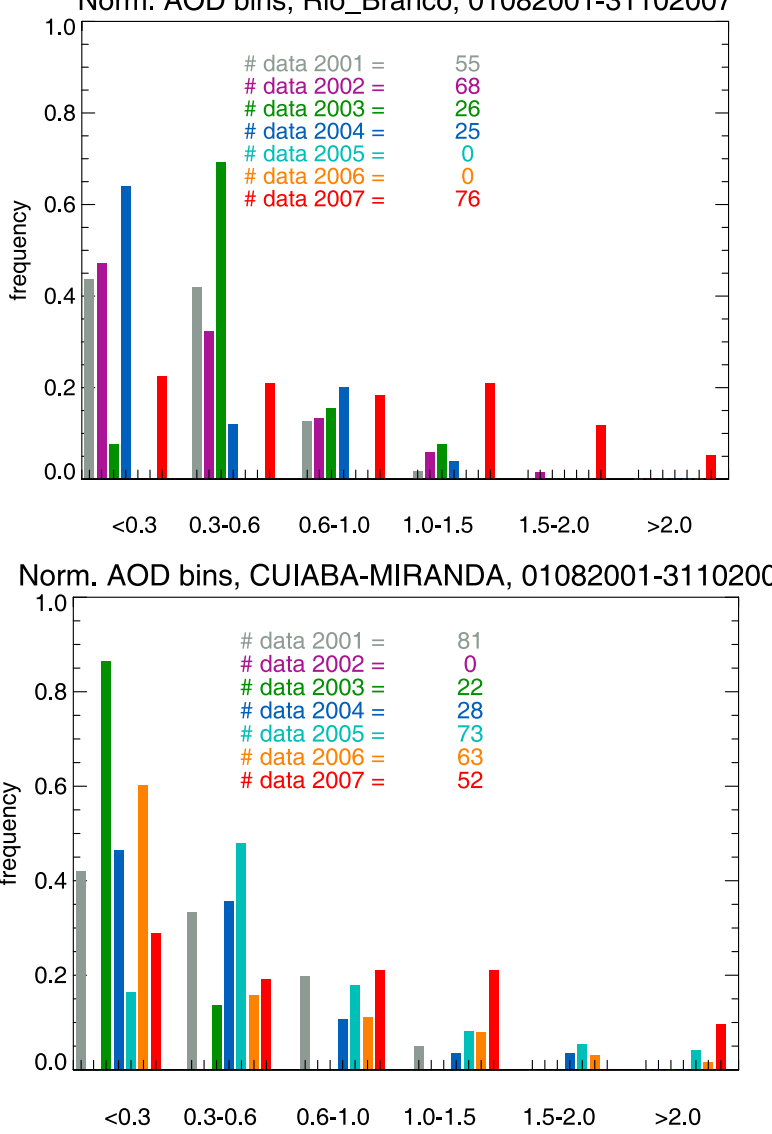

Norm. AOD bins, CEILAP-BA, 01082001-31102007

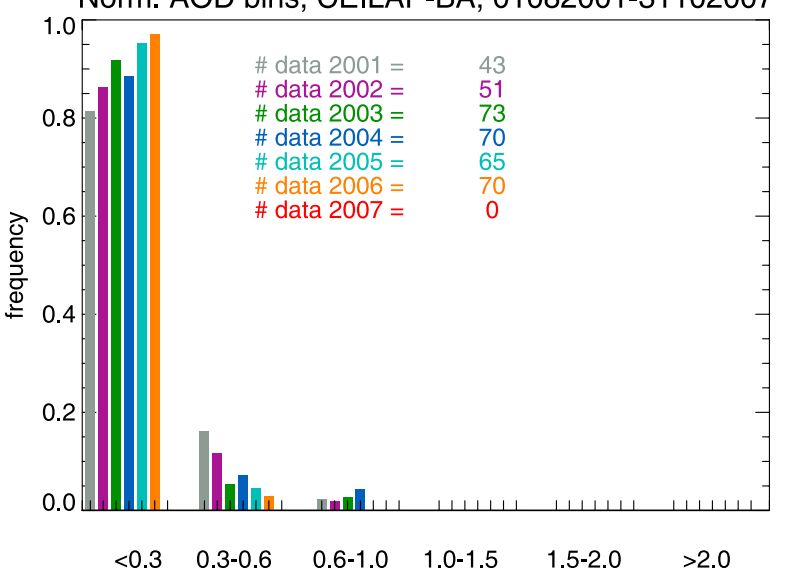

Figure 6. Normalized histograms of AERONET AOD bins at different sites for years 2001-2007, during typical MODIS/TERRA overpass period.

varying maximum AOD below 0.3 between September and December, which may be related to fires.

[30] Table 1 provides absolute values of the biomass burning season mean AERONET AOD, its standard deviation, and absolute AOD maxima separately for TERRA and AQUA overpass time throughout all seven burning seasons from 2001 to 2007. Considerably higher maximum AOD values can be observed for sites that are either located in regions with high biomass burning activity, or in adjacent regions influenced by smoke transport, than those sites located elsewhere. The highest AOD (4.0) is observed during an overpass by TERRA over Alta Floresta. Generally, standard deviations are high, in the order of the mean values, which indicate the high variability of AOD during the biomass burning seasons. Sites located in megacities yield a considerable lower annual August-October mean $(<0.3)$ and maximum AOD $(<1.4)$ (Table 1) than AERONET sites located in the purely biomass burning influenced regions.

[31] To demonstrate the occurrence of high AOD and typical distributions at each AERONET site we present six AOD bins as histograms, comprising all available years of data (Figure 6). Results are presented for mean AERONET 
AOD at TERRA overpass time during morning, and were compared to those measured during typical AQUA overpass time (not shown), independent if MODIS observations are available for this time slot or not. Since the histograms are very similar and the TERRA time AOD yields more data points and the whole suite of years, only AOD at TERRA the overpass period is presented. Alta Floresta, Rio Branco and Cuiabá-Miranda, the biomass burning influenced sites, show high AOD's for the years 2005-2007, and to a somewhat lesser extent, also for 2002 (Alta Floresta). Most AOD data points are however located in the AOD range from 0.3 to 0.6 , followed by the AOD bin 0.6-1.0. The urban AERONET sites, such as São Paulo and Buenos Aires (CEILAP-BA), only observed AOD's with values in the $<0.3$ range and with few values in the $0.3-0.6 \mathrm{bin}$.

\subsection{Isotropic Representativity of AERONET Sites}

[32] Figures 7-9 present the results of the isotropic, spatial correlation study described in section 3 . We have chosen the AERONET site of Alta Floresta as a typical example how correlations behave during the burning seasons (August to October) from 2001 to 2007. In Figure 7a correlations are presented for MODIS/TERRA and correspondent AERONET hourly mean AOD. Generally, it can be observed that (1) $\mathrm{R}^{2}$ correlations are high $(>0.7),(2)$ as linear regression yields a slope $>1$ MODIS tends to overestimate AOD, except for low AOD values, and (3) no apparent interannual trend of correlation or slope can be found from 2001 to 2007. Especially at the site Alta Floresta it was expected that the strong land cover change occurring in the vicinity of this site, associated to deforestation processes and thus, fire activity, could provoke a trend in correlation patterns along the years: The forest line, and thus the region of deforestation activity, is continuously receding from Alta Floresta, which might be visible in local measurements of AOD, but not on a low-resolution remote sensing AOD product. Since no trend could be observed for any of the sites, the latter item suggests a compilation of all years data to provide a more solid statistical basis by augmenting the number of record elements $(\mathrm{N})$, as shown in the bottom right of Figure $7 \mathrm{a}$ and $7 \mathrm{~b}$ for Alta Floresta. Properties 1-3 prevail for all AERONET sites subject to biomass burning emissions, and thus elevated AOD during the burning season. The patterns are repeated in the correlation study with MODIS/AQUA AOD (Figure 7b). AOD correlation based on all years (2001-2007) of other AERONET sites are shown in Figure 8 . The patterns 1 to 2 are the same as for Alta Floresta, except for the urban sites with an AOD $<1$. The threshold in pattern 2, where the systematic bias between AERONET and MODIS AOD is inverted, varies between an AOD of 0.3 and 0.7 .

[33] These correlation results are in contrast to the global validation of the MODIS AOD C3 and C4 product by Remer et al. [2005]. A corresponding global correlation value for data points over land presents a positive MODIS for small AOD's and an underprediction for high values. Since these results are based on global data and for the period 2000-2002 it is most certainly not representative for specific conditions in South America. Further, the MODIS C4 algorithm validated by Remer et al. [2005] employs a nondust, moderate absorption aerosol model (applied to regions under influence of forest smoke and urban emis- sions in developing countries) in South America. This aerosol model uses a single scattering albedo $\omega_{\mathrm{o}}(550 \mathrm{~nm})$ $=0.90$ for the whole year and continent. The optical aerosol property $\omega_{\mathrm{o}}$ can determine the sign of radiative forcing, i.e., cooling or heating [Hansen et al., 1997], and is thus crucial for a correct representation of the aerosol load in the atmosphere. AERONET ground retrievals presented in the work of Dubovik et al. [2002] yield a higher $\omega_{\mathrm{o}}$ at $550 \mathrm{~nm}$ for Amazonian forest (0.94) and a lower for Brazilian Cerrado (0.90). In situ measurements reported by Dubovik et al. [2002] present lower numbers, such as $\omega_{\mathrm{o}}=0.86$ for Amazonian forest, $\omega_{\mathrm{o}}=0.79$ (local smoke) and $\omega_{\mathrm{o}}=0.85$ (aged smoke) for Cerrado [Reid et al., 1998]. These differences in the single scattering albedo may significantly change aerosol load calculations for remote sensing products, however intercomparison with in situ data needs to be handled with caution owing to representativeness errors.

[34] The MODIS C5 AOD product used in this study makes use of updated aerosol model look up tables (LUT's). On the global scale, the MODIS C5 product seems to be considerably improved, but still somewhat overestimates AOD compared to AERONET data [Levy et al., 2007b]. However, to conclude on a regional scale the product needs to be analyzed in more detail: Levy et al. [2007a] performed a subjective seasonal cluster analysis with AERONET data to produce new LUT's with more realistic regional optical properties. A triangle, comprising the region of southern central Brazil and the southeastern region of Brazil, is now attributed to the highly absorbing aerosol model from June to November with $\omega_{\mathrm{o}}=0.85$, formerly only applied to Southern Africa. However, it remains unclear with Figures 2 and 3 presented by Levy et al. [2007a], which of the AERONET sites are exactly located in this triangle for highly absorbing aerosol. During the remaining year and other parts of the Southern American continent, the moderately absorbing aerosol model is assumed with $\omega_{\mathrm{o}}=0.90$, such as in the earlier C4 version. The cluster analysis chooses the predominant fraction of the assigned aerosol model to each AERONET observation separately for the seasons DJF, MAM, JJA, and SON. The main burning season in central Brazil takes place from August to September. Possibly, both the seasons JJA and SON defined in the study include a number of AERONET measurements before the onset and after the offset of the burning season, thus finding a high percentage of moderately absorbing aerosol, which may lead to a nonrepresentative attribution of optical aerosol properties to the observation sites located in northeastern central Brazil. The result would be exactly the overestimate in AOD observed during the burning season from August to October, due to an unrealistically highly absorbing aerosol model that does not reflect Southern American conditions. A recent AERONET climatology study by Schafer et al. [2008] shows that the typical single scattering albedo for Cerrado (such as in Cuiabá) is $\omega_{\mathrm{o}}=$ 0.89 and for southern Amazonian sites it is $\omega_{\mathrm{o}}=0.92$. These numbers further indicate that the MODIS aerosol model for South America requires a higher single scattering albedo assumption during the burning season than can presently be found in the MODIS C5 AOD product.

[35] To derive isotropic radii of influence from the present correlation study we investigated how the correlation behave when expanding the MODIS area and using differ- 

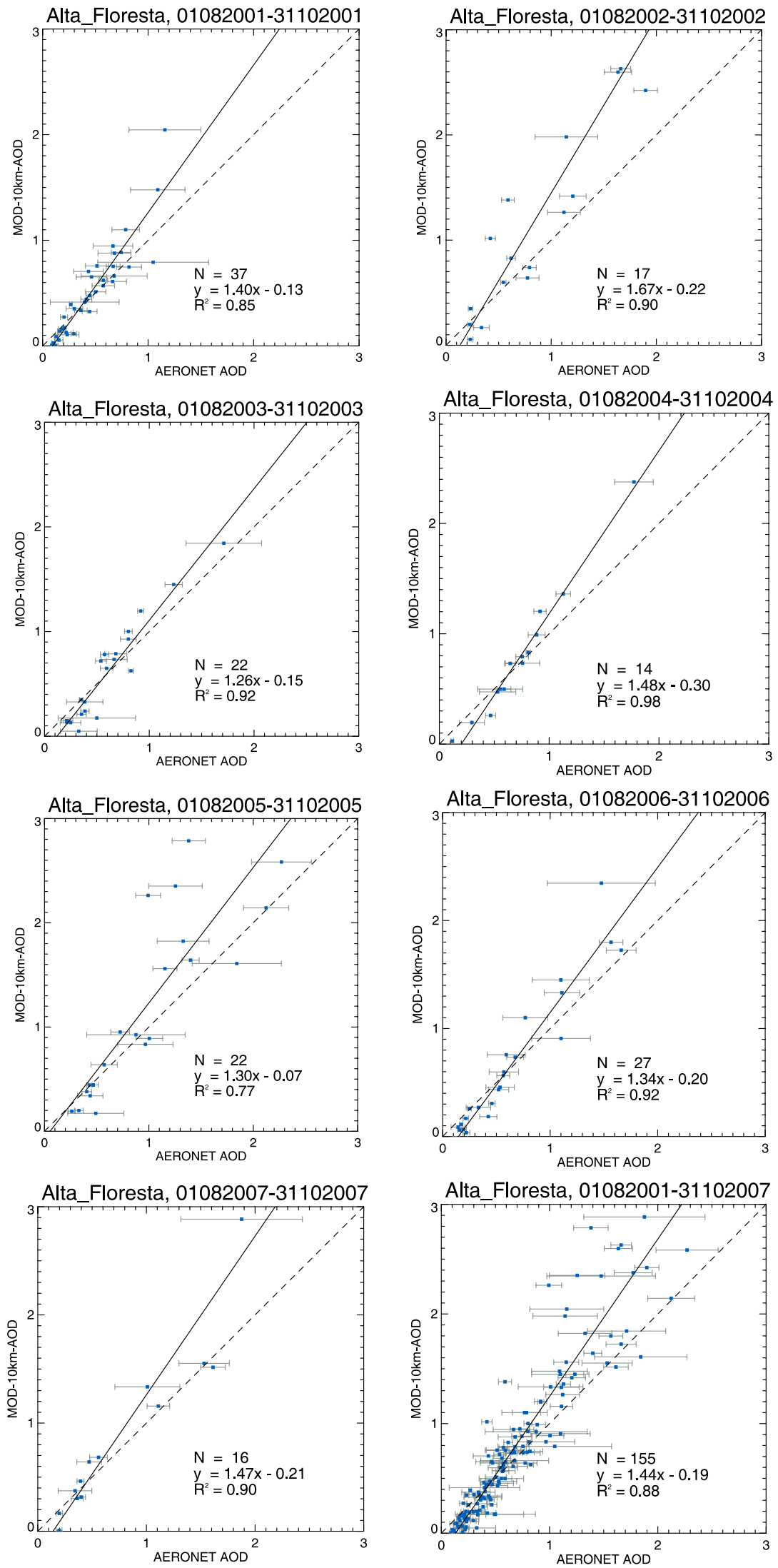

Figure 7a. Scatterplot of MODIS/TERRA and AERONET AOD $550 \mathrm{~nm}$ at Alta Floresta for the burning seasons (August-October) for each year from 2001 to 2007 and integrated over the full period (bottom right). AERONET values are hourly means centered at TERRA overpass time. 

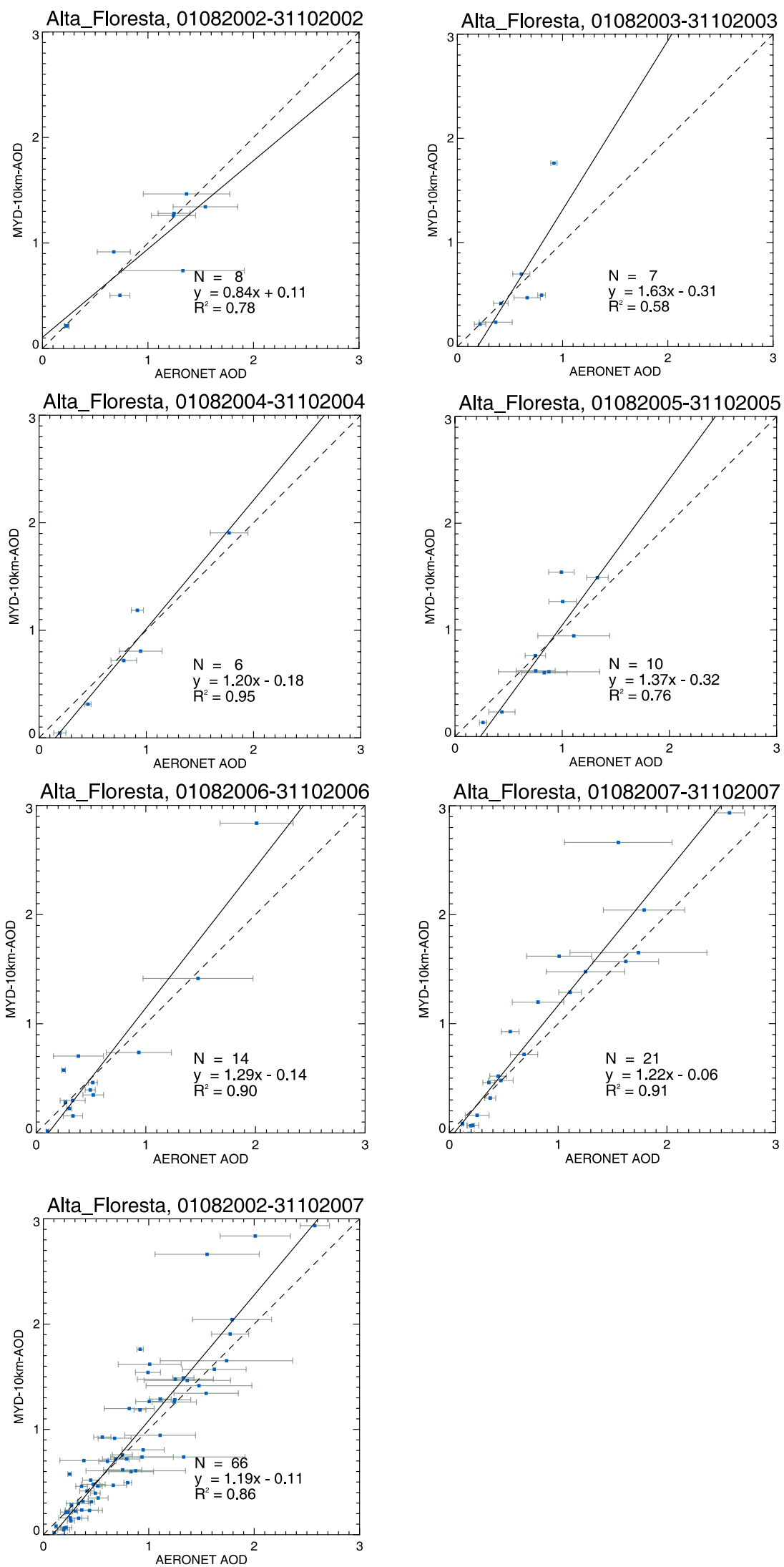

Figure 7b. Scatterplot of MODIS/AQUA and AERONET AOD $550 \mathrm{~nm}$ at Alta Floresta for the burning seasons (August-October) for each year from 2003 to 2007 and integrated over the full period (bottom right). AERONET values are hourly means centered at AQUA overpass time. 

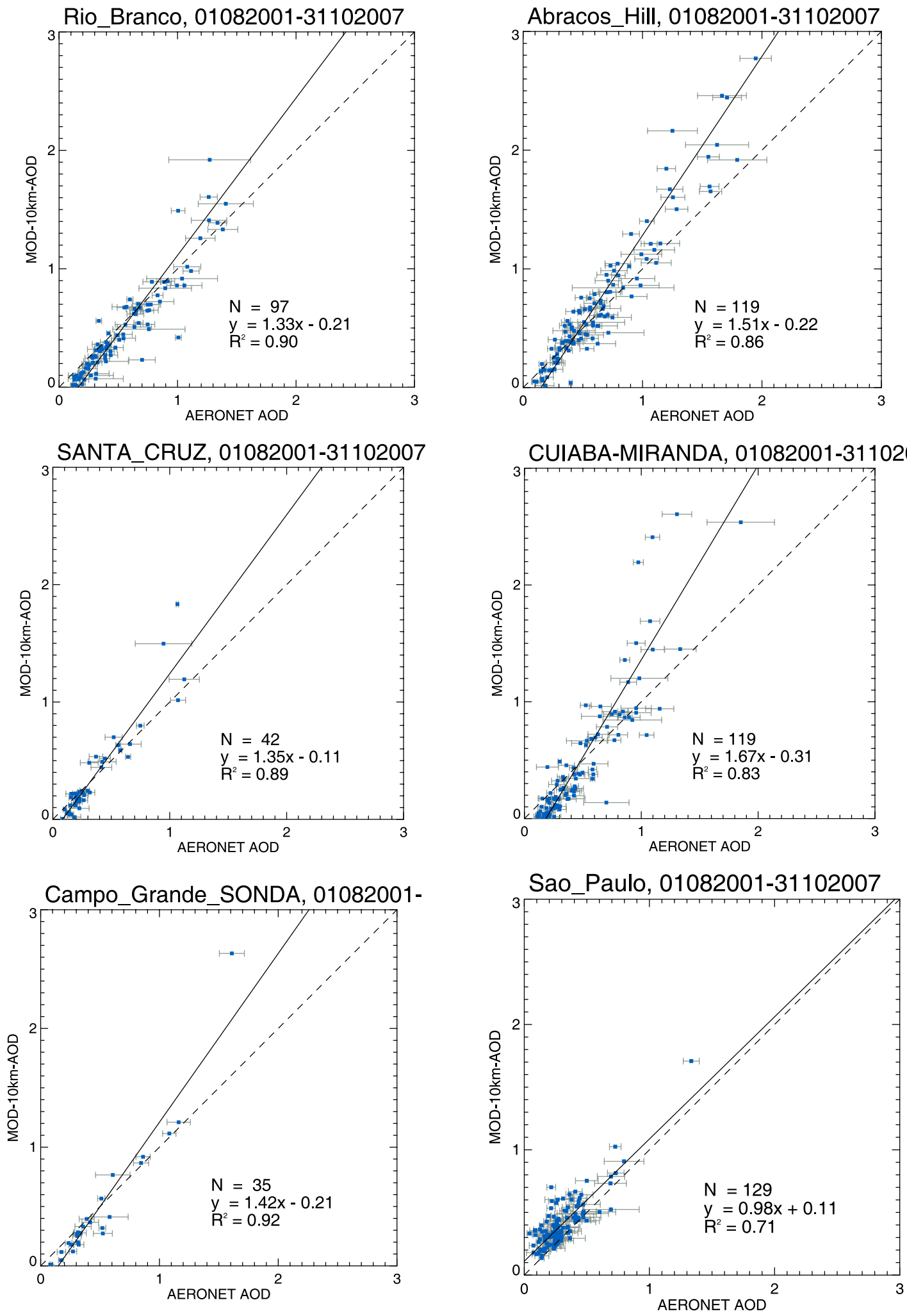

Figure 8. Scatterplot of MODIS/TERRA and AERONET AOD at $550 \mathrm{~nm}$ integrated from 2001 to 2007 at all remaining AERONET sites.

ent sizes of spatial averages of MODIS AOD around each AERONET site, as described in section 3. Results for all AERONET sites behave very similar, therefore an example of this approach is depicted in Figure 9 only for the site of
Rio Branco, located in the state Acre of northwestern Brazil. In Figures 9a to $9 \mathrm{~d}$ the spatial area where MODIS AOD is averaged is increased from $10 \mathrm{~km} \times 10 \mathrm{~km}$ (1 MODIS pixel $), 30 \mathrm{~km} \times 30 \mathrm{~km}(9$ pixels $), 50 \mathrm{~km} \times 50 \mathrm{~km}$ 

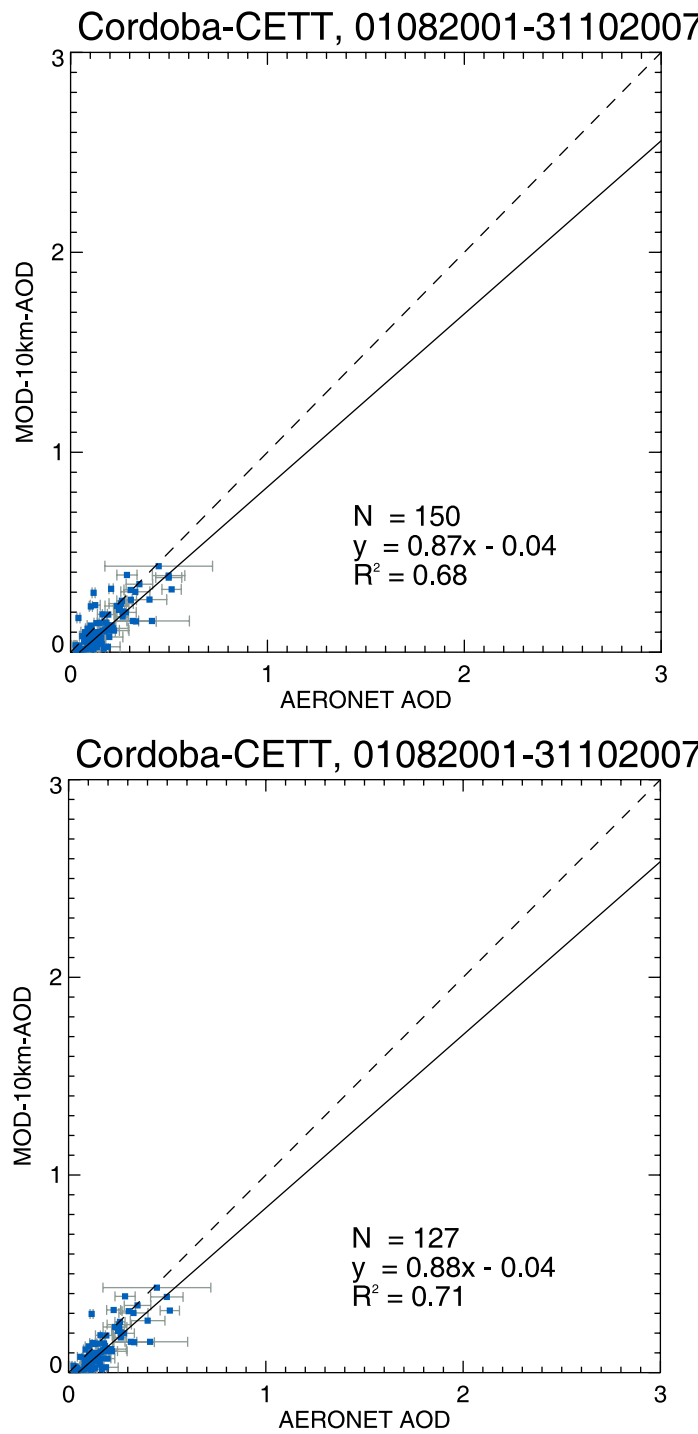
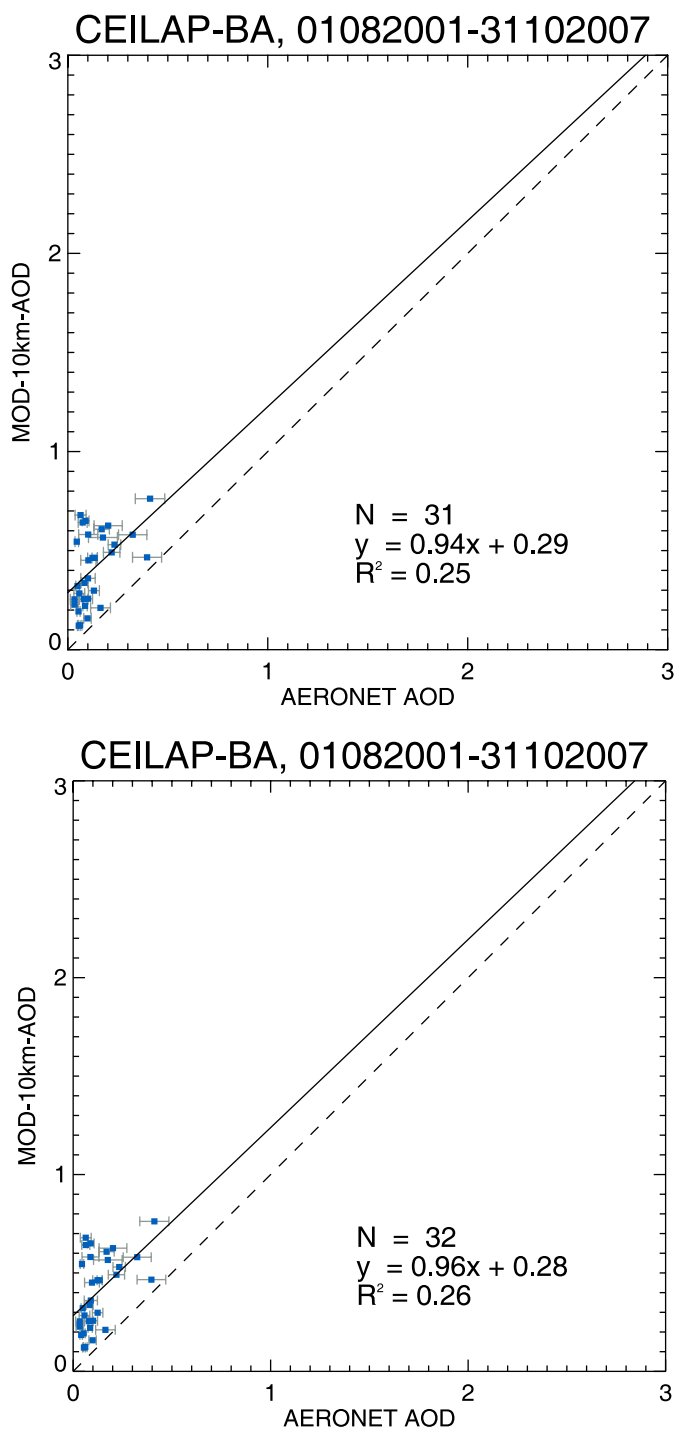

Figure 8. (continued)

(25 pixels), to $150 \mathrm{~km} \times 150 \mathrm{~km}$ (225 pixels). This spatial MODIS AOD average is then correlated with the site's AERONET AOD. Rio Branco is highly affected by fires during the burning season. These fires occur mostly in the Amazonian region and central Brazil, however, by atmospheric transport, their emissions produce a spatial smoke distribution over a large area of about 3-5 million $\mathrm{km}^{2}$ [Artaxo et al., 2006]. This is considerably higher than the area where the fires sources are concentrated [Freitas et al., 2005, 2007a]. Therefore, spatial correlations remain very high, even when applying an AOD value, spatially averaged over a very large area of $150 \mathrm{~km} \times 150 \mathrm{~km}$, to calculate AOD correlations. In fact, the larger the averaged area, the stronger the tendency that the linear regression slope goes toward the value 1 . The same is true for all other sites that are located in this fire-impacted region (not shown). On one side this means that a large radius of influence may be suitable for these sites. However, the isotropy of this approach possibly ignores that various subregions within the reach of this radius may inhere a different scenario, and thus infers a representativity error. One possibility would be to refine this isotropic approach, such as Kovacs [2006], who calculated correlations of equidistant pixels around a site.

[36] In his study we have opted for an anisotropic approach (section 5.3) that will be able to provide a preferential treatment to geographical directions that yield higher correlations. Derived from a sound statistical basis, these areas of influence will be more adequate for later data assimilation purposes.

\subsection{Anisotropic Representativity of AERONET Sites}

[37] A more sophisticated approach than isotropic influence radii is the use of more realistic anisotropic areas of influence for each AERONET site, calculated according to the methodology in section 4 . The resulting AOD correlation arrays over South America for each AERONET site with regard to all MOVAS TERRA (top) and AQUA (bottom) AOD grid boxes for the burning seasons from 2001 to 2007 are shown in Figure 10. The AERONET sites 

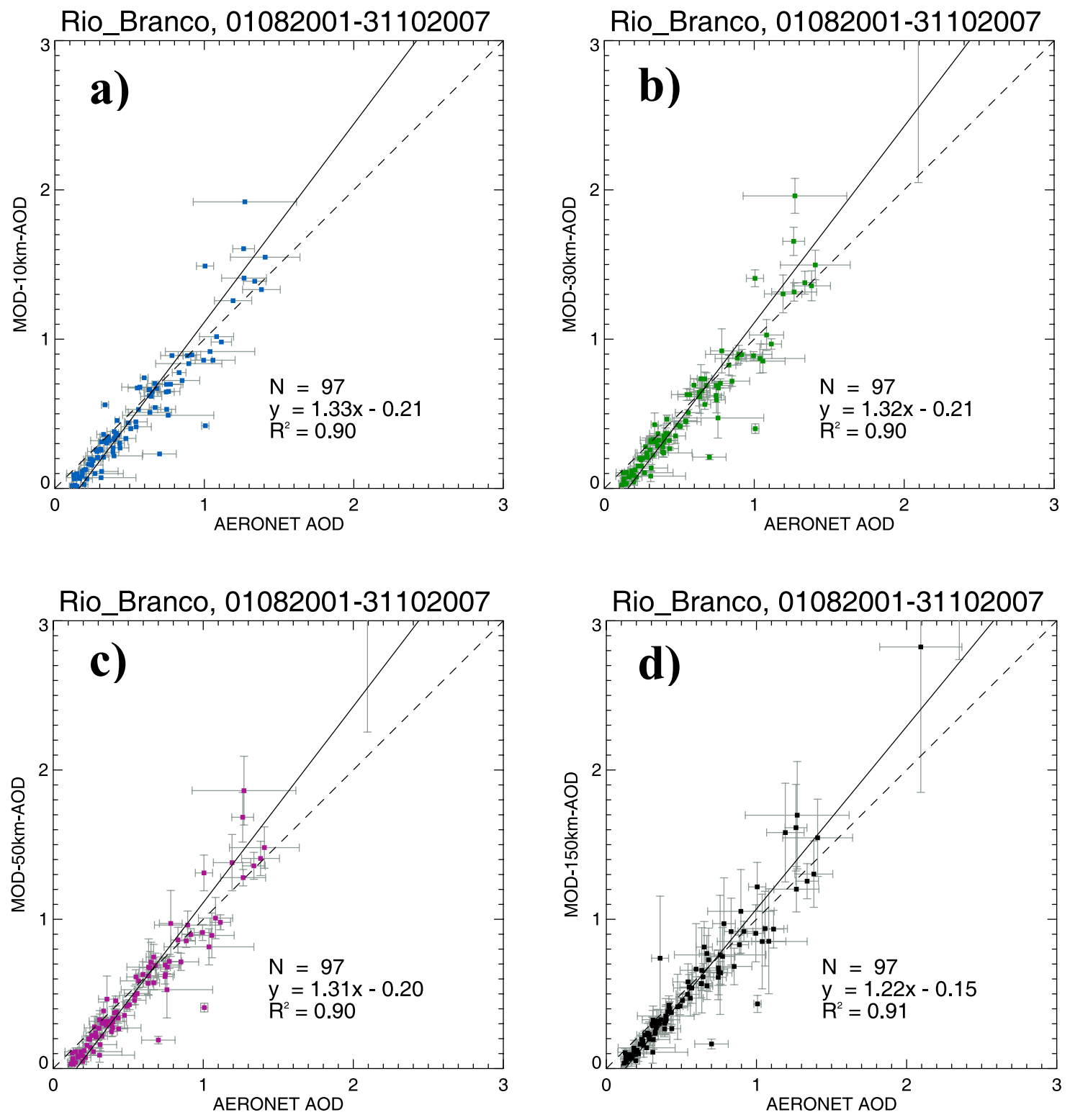

Figure 9. Scatterplot of MODIS/TERRA and AERONET AOD at $550 \mathrm{~nm}$ integrated from 2001 to 2007 at Rio Branco for (a) MODIS $10 \mathrm{~km}$, (b) MODIS $30 \mathrm{~km}$, (c) MODIS $50 \mathrm{~km}$, and (d) MODIS $150 \mathrm{~km}$ spatial average around the AERONET site.

Belterra, Santiago and Petrolina were excluded from this step as a solid amount of data is missing to support reliable statistics and these sites are not located in the main region of interest with high impact of biomass burning activity. Most sites present strongly anisotropic and inhomogeneous shape of area with moderate to strong AOD correlations with MOVAS. Rio Branco, Santa Cruz, and Campo Grande yield the largest areas of influence, spreading over several state and country borders. A noticeable pattern is the northwestern transport of biomass burning emission loaded air and, to a lesser extent, also toward the southeastern direction, especially notable for Santa Cruz and Campo Grande. The sites Abracos Hill, Alta Floresta and Cuiabá-Miranda show smaller and more isotropic radii of influence, but the correlation clearly show that observations from these sites may be used to exploit the measurements for much larger areas for assimilation-based chemical state analyses and model initialization. The appearance of the obtained areas of influence can be explained with climatological meteorological patterns over South America: generally, during the dry season, central Brazil is dominated by a high pressure area with low precipitation and light winds in the lower troposphere [Satyamurty et al., 1998]. Convection in the Amazon basin is shifted to the northwestern part of South America. These conditions are associated with the westward displacement of the South Atlantic Subtropical High (SASH) and the northward motion of the Intertropical Convergence Zone (ITCZ) during the austral winter. The position of the SASH determines the inflow of clean maritime air into the biomass burning area, playing an 

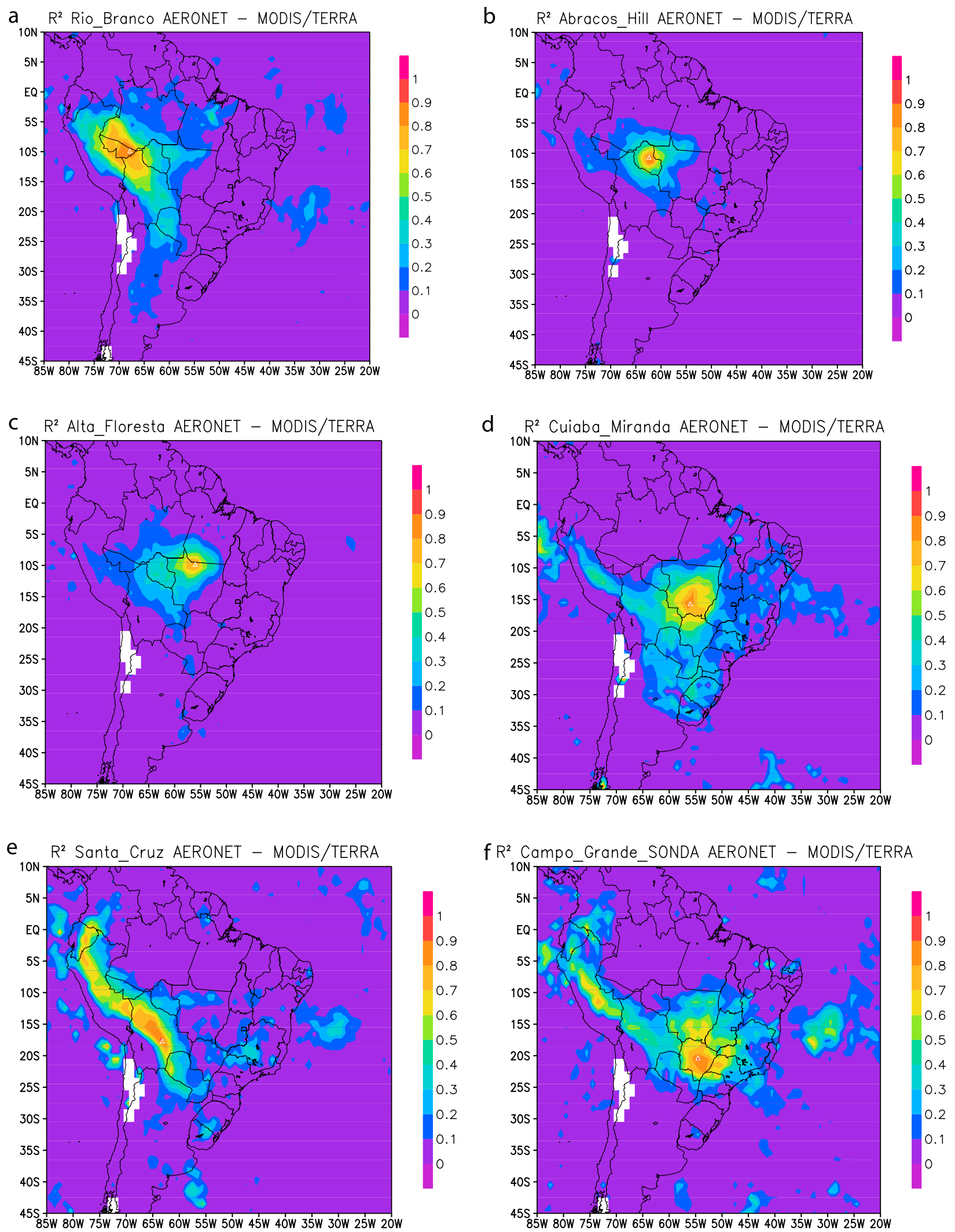

Figure 10. Gridded correlations of individual AERONET sites in South America for data assimilation purposes, calculated by correlation studies of AERONET and MODIS/TERRA (MOVAS $1 \times 1$ ) AOD at $550 \mathrm{~nm}$ for the burning seasons (August-October) from 2001 to 2007. Plotted AERONET sites: (a) Rio Branco (3), (b) Abracos Hill (1), (c) Alta Floresta (4), (d) Cuiabá-Miranda (2), (e) Santa Cruz (8), (f) Campo Grande Sonda (5), (g) São Paulo (9), (h) Ceilap-BA (6), and (i) Cordoba-CETT (7). Numbers in parentheses refer to the color bar in Figure 11. 

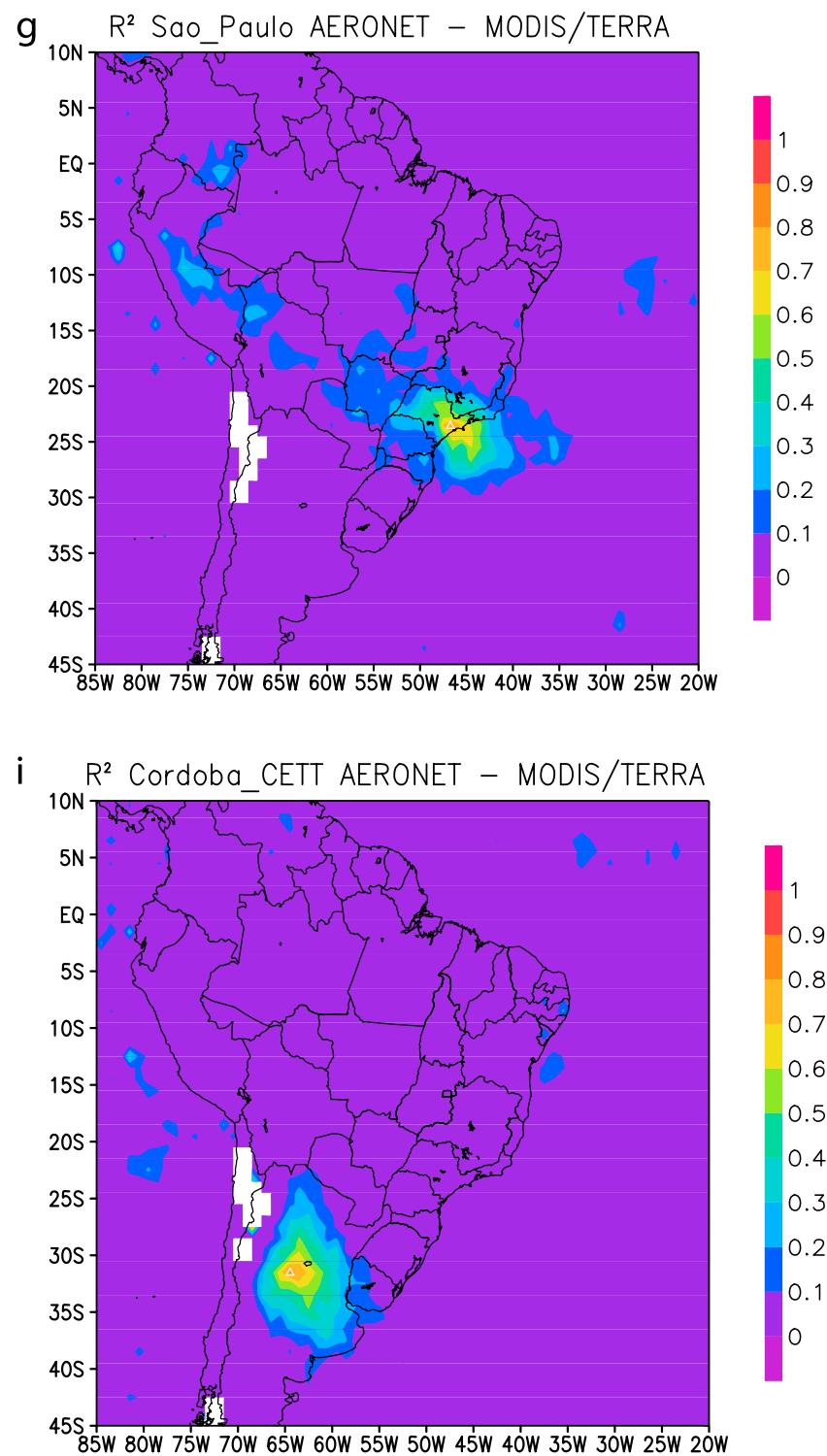

Figure 10 .

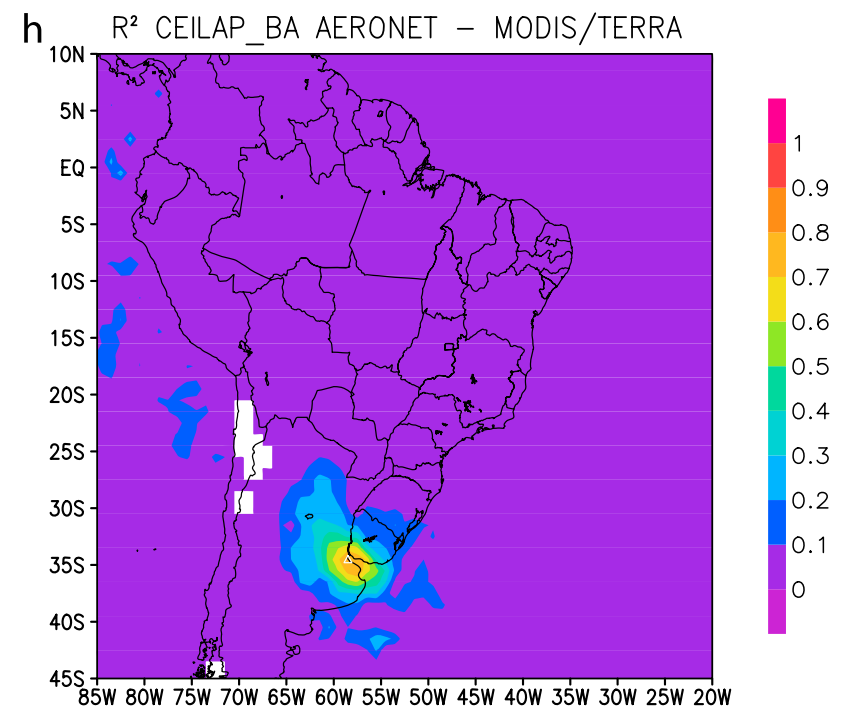

important role in defining the shape of regional smoke plumes, as the SASH is the primary mechanism responsible for dilution of polluted air. Approaching cold frontal systems from the south are responsible for disturbances in atmospheric stability and in the wind field. These changes define the main corridors of smoke export to oceanic areas. The Andes Mountains on the east side of South America, together with the SASH, impose a long-range transport of smoke from its source areas to the South and Southeast of the South American continent, thus disturbing larger areas downwind in the subtropics. The two major areas of inflow and outflow are north of the Equator with the inflow of smoke from African fires and a smoke outflow from SA fires to the Southern Atlantic Ocean and to the African continent [Freitas et al., 2007b].

[38] In Figure 11 the individual correlations obtained in Figure 10 were compiled to a single map with dominant influence areas for each site. Each color of Figure 11 represents the radius of influence of a specific site, denominated in legend of Figure 11 and in the legend of Figure 10. The radii of influence were restricted to correlations of $\mathrm{R}^{2}>$ 0.5 . In addition, a conservative approach has been chosen that fulfills a continuity criterion: the areas of influence may remain contingent, thus only connected grid points starting from the site's location are considered. Spurious grid points with high correlations were excluded from the final map.

[39] TERRA results (Figure 11a) generally yield similar patterns as those from AQUA (Figure 11b), with some differences in detail: the AQUA influence area of Santa Cruz and Rio Branco do not extent as far into northern Peru as with TERRA, the influence areas for Abracos Hill and Cuiabá-Miranda are smaller, and Buenos Aires AOD's yields correlations $\mathrm{R}^{2}>0.5$ and thus a notable correlation length. In summary, Figure 11 shows that in spite of the sparseness of local measurement sites, a significant area of 
Anisotropic radii of influence AERONET - MODIS/TERRA

a)

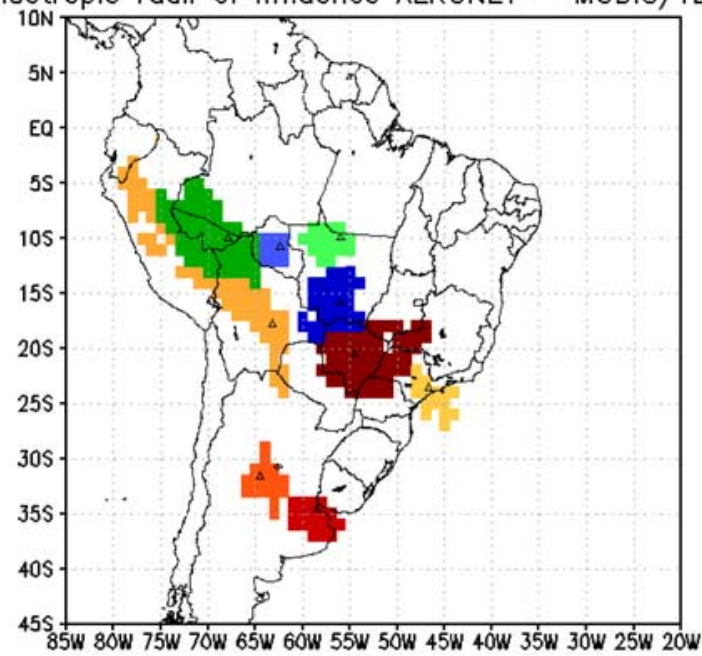

Anisotropic radii of influence AERONET - MODIS/AQUA

b)

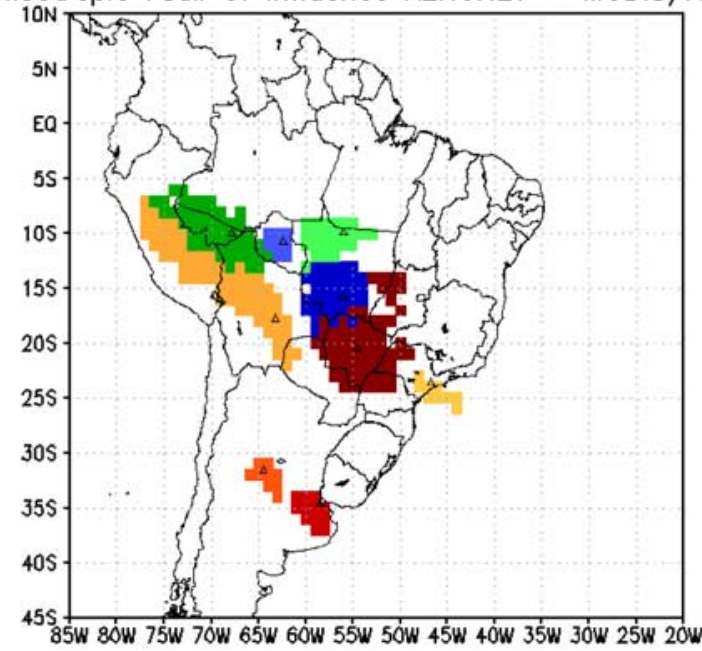

Figure 11. Anisotropic radii of influence of AERONET sites in South America for data assimilation purposes, calculated by correlation studies of AERONET and MODIS $\left(\right.$ MOVAS $1^{\circ} \times 1^{\circ}$ ) (a) TERRA and (b) AQUA AOD at $550 \mathrm{~nm}$. Plotted AERONET sites: Abracos Hill (1), Cuiabá-Miranda (2), Rio Branco (3), Alta Floresta (4), Campo Grande Sonda (5), Ceilap-BA (6), Cordoba-CETT (7), Santa Cruz (8), and São Paulo (9). Numbers in parentheses refer to the color bar.

South America may be characterized by AERONET AOD observations.

\section{Conclusions}

[40] In this paper we present an intercomparison study of MODIS satellite and ground-based remote sensing AOD observations in South America over the years 2001-2007, with special focus on observations sites with a strong influence of fire emissions during the biomass burning season. The objectives were to investigate possible trends of the time series, differences between TERRA and AQUA
MODIS AOD, and to establish regional representativity criteria for the South American AERONET sites that may be used for AOD assimilation into a Chemistry Transport Model.

[41] Generally, all biomass burning influenced sites show a distinct augmentation in AOD during the burning seasons of all years (August-October) with a maximum in September. AOD at urban sites is considerably lower than at the fire influenced sites. These features are equally well represented by AERONET and MODIS satellite data. The correlation study, carried out for the biomass burning season from August to October for the year 2001-2007, separately for TERRA and AQUA data, revealed that AERONET and MODIS data correlate generally well $\left(\mathrm{R}^{2}>0.7\right)$, with a slope bigger than 1. MODIS data over South America yield a systematic bias: AOD is too low for small AOD values and yields a high bias for elevated AOD's. For later data assimilation purposes these systematic biases can be corrected during assimilation. No interannual trend of correlation or slope could be found during the investigated period. Statistically, no large differences could be observed between MODIS/TERRA and MODIS/AQUA data. However, it will be useful to allow a separate assimilation into a model, to make use of the temporal resolution, given by the two different overpass times.

[42] The isotropic radii of influence derived for each AERONET site allow a spatial distribution of observation validity over the model domain. However, they need to be used with caution to not infer gross errors of representativeness. The more sophisticated anisotropic approach provided strongly inhomogeneous and anisotropic areas of influence based on AOD data for the burning seasons from 2001 to 2007. These climatological influence areas cover large regions of the continent for some sites, which in the future may have transboundary implications related to emission transport.

[43] An influence map was derived for all observation sites that may directly be used by AOD assimilation schemes, whose background error covariance matrix is prepared to deal with anisotropic areas of influence. Such systems will highly profit from these newly defined parameters, by distributing assimilated information on AERONET AOD to neighboring grid points, based on sound statistics. The influence maps developed during the present study will be used with the CCATT-BRAMS model at CPTEC/INPE. The additional assimilation of AERONET AOD using these newly derived areas of influence is expected to strongly contribute to an improvement of the model skill.

[44] The anisotropic areas of influence map further pinpoints regions where additional AOD measurement sites are needed to allow for a more complete observation coverage of the South American continent. Beyond these technical aspects, they also indicate areas of common aerosol chemistry regimes and their related geographical environmental impact.

[45] Our correlation study of MODIS versus AERONET AOD reaffirmed the importance of a regional MODIS algorithm for AOD retrieval over South America with adequate optical aerosol models. Pioneering work on this topic has been contributed by A. L. Correia (Monitoring aerosol optical depth using MODIS over Brazil and South America, paper presented at Congresso Brasileiro de Meteorologia, 2006, Anais do Congresso Brasileiro de Meteor- 
ologia, Florianópolis, 2006) and Correia et al. [2006] over biomass burning smoke influenced areas and by de Almeida Castanho et al. [2008] over the megacity São Paulo. For aerosol data assimilation in South America it would be fundamental that this work be continued until achieving an operational status.

[46] Acknowledgments. Judith Hoelzemann is funded by the Brazilian "Fundação de Amparo à Pesquisa do Estado de São Paulo" (FAPESP) under grant $05 / 60890-3$. This work was carried out with support by FAPESP project $(2008 / 06822-4)$ and the InterAmerican Institute for Global Change Research (IAI) CRN II 2017, supported by the U.S. National Science Foundation (grant GEO-0452325). We thank the AERONET principal investigators Brent Holben, Paulo Artaxo, and Enio B. Pereira and their staff for establishing and maintaining the South American sites used in this investigation, the NASA/MODAPS team for providing the whole suite of MODIS collection 5 data, the NASA/MOVAS/Giovanni team at GES DISC for provision of gridded MODIS data, and two anonymous reviewers who provided very helpful comments that contributed substantially to improve this paper.

\section{References}

Abdou, W. A., D. J. Diner, J. V. Martonchick, C. J. Bruegge, R. A. Kahn, B. J. Gaitley, and K. A. Crean (2005), Comparison of coincident Multiangle Imaging Spectroradiometer and Moderate Resolution Imaging Spectroradiometer aerosol optical depths over land and ocean scenes containing Aerosol Robotic Network sites, J. Geophys. Res., 110, D10S07, doi:10.1029/2004JD004693.

Albrecht, B. A. (1989), Aerosols, cloud microphysics, and fractional cloudiness, Science, 245, 1227-1230, doi:10.1126/science.245.4923.1227.

Andreae, M. O., et al. (2001), Transport of biomass burning smoke to the upper troposphere by deep convection in the equatorial region, Geophys. Res. Lett., 28, 951-954, doi:10.1029/2000GL012391.

Artaxo, P., V. G. Gatti, A. M. C. Leal, K. M. Longo, S. R. de Freitas, L. L. Lara, T. M. Pauliquevis, A. S. Procópio, and L. V. Rizzo (2005), Química atmosférica na Amazônia: A floresta e as emissões de queimadas controlando a composição da atmosfera amazônica, Acta Amazon., 35(2), 191-208, doi:10.1590/S0044-59672005000200008.

Artaxo, P., P. H. Oliveira, L. L. Lara, T. M. Pauliquevis, L. V. Rizzo, C. Pires, M. A. Paixão, K. M. Longo, S. Freitas, and A. L. Correia (2006), Efeitos climáticos de partículas de aerossóis biogênicos e emitidos em queimadas na Amazônia, Rev. Bras. Meteorol., 21(3), 168-189.

Christopher, S. A., J. Chou, J. Zhang, X. Li, and R. M. Welch (2000), Shortwave direct radiative forcing of biomass burning aerosols estimated from VIRS and CERES, Geophys. Res. Lett., 27, 2197-2200, doi:10.1029/1999GL010923.

Chu, D. A., Y. J. Kaufman, G. Zibordi, J. D. Chern, J. Mao, C. Li, and B. N. Holben (2003), Global monitoring of air pollution over land from the Earth Observing System-Terra Moderate Resolution Imaging Spectroradiometer (MODIS), J. Geophys. Res., 108(D21), 4661, doi:10.1029/ 2002JD003179.

Correia, A. L., A. D. Castanho, J. V. Martins, K. M. Longo, M. A. Yamasoe, and P. Artaxo (2006), Inferência de Aerossóis, in O sensor MODIS e suas aplicações ambientais no Brasil, pp. 297-314, Bookimage, São José dos Campos, Brazil.

de Almeida Castanho, A. D., J. Vanderlei Martins, and P. Artaxo (2008), MODIS Aerosol Optical Depth retrievals with high spatial resolution over an urban area using the critical reflectance, J. Geophys. Res., 113, D02201, doi:10.1029/2007JD008751.

Dubovik, O., B. N. Holben, T. F. Eck, A. Smirnov, Y. J. Kaufman, M. D. King, D. Tanre, and I. Slutsker (2002), Variability of absorption and optical properties of key aerosol types observed in worldwide locations, J. Atmos. Sci., 59, 590-608, doi:10.1175/1520-0469 (2002) $059<0590$ :VOAAOP $>2.0$.CO;2.

Elbern, H., A. Strunk, H. Schmidt, and O. Talagrand (2007), Emission rate and chemical state estimation by 4-dimensional variational inversion, Atmos. Chem. Phys., 7, 3749-3769.

Forster, P., et al. (2007), Changes in atmospheric constituents and in radiative forcing, in Climate Change 2007: The Physical Science Basis. Contribution of Working Group I to the Fourth Assessment Report of the Intergovernmental Panel on Climate Change, edited by S. Solomon et al., pp. 180-185, Cambridge Univ. Press, New York.

Freitas, S., K. Longo, M. A. F. Silva Dias, P. L. Silva Dias, R. Chatfield, E. Prins, P. Artaxo, G. Grell, and F. Recuero (2005), Monitoring the transport of biomass burning emissions in South America, Environ. Fluid Mech., 5, 135-167.
Freitas, S. R., K. M. Longo, R. Chatfield, D. Latham, M. A. F. Silva Dias, M. O. Andreae, E. Prins, J. C. Santos, R. Gielow, and J. A. Carvalho Jr. (2007a), Including the sub-grid scale plume rise of vegetation fires in low resolution atmospheric transport models, Atmos. Chem. Phys., 7, $3385-3398$.

Freitas, S. R., et al. (2007b), The coupled aerosol and tracer transport model to the Brazilian developments on the regional atmospheric modeling system (CATT-BRAMS): Part 1. Model description and evaluation, Atmos. Chem. Phys. Discuss., 7, 8525-8569.

Hansen, J., M. Sato, and R. Ruedy (1997), Radiative forcing and climate response, J. Geophys. Res., 102, 6831-6864, doi:10.1029/96JD03436.

Hauser, A., D. Oesch, and N. Foppa (2005), Aerosol optical depth over land: Comparing AERONET, AVHRR and MODIS, Geophys. Res. Lett., 32, L17816, doi:10.1029/2005GL023579.

Holben, B. N., et al. (1998), AERONET a federated instrument network and data archive for aerosol characterization, Remote Sens. Environ., 66, 1-16, doi:10.1016/S0034-4257(98)00031-5.

Ichoku, C., L. A. Remer, and T. F. Eck (2005), Quantitative evaluation and intercomparison of morning and afternoon Moderate Resolution Imaging Spectroradiometer (MODIS) aerosol measurements from Terra and Aqua, J. Geophys. Res., 110, D10S03, doi:10.1029/2004JD004987.

Kaufman, Y. (1995), Remote sensing of direct and indirect aerosol forcing, in Aerosol Forcing of Climate, edited by R. J. Charlson and J. Heintzenberg, pp. 297-332, John Wiley, New York.

Kaufman, Y. J., and R. S. Fraser (1997), The effect of smoke particles on clouds and climate forcing, Science, 277, 1636-1639, doi:10.1126/ science.277.5332.1636

Kinne, S., et al. (2003), Monthly averages of aerosol properties: A global comparison among models, satellite data, and AERONET ground data, J. Geophys. Res., 108(D20), 4634, doi:10.1029/2001JD001253.

Koren, I., Y. J. Kaufman, L. A. Remer, and J. V. Martins (2004), Measurement of the effect of Amazon smoke on inhibition of cloud formation, Science, 303, 1342-1345, doi:10.1126/science.1089424.

Kovacs, T. (2006), Comparing MODIS and AERONET aerosol optical depth at varying separation distances to assess ground-based validation strategies for spaceborne lidar, J. Geophys. Res., 111, D24203, doi:10.1029/2006JD007349.

Levy, R. C., L. A. Remer, and O. Dubovik (2007a), Global aerosol optical properties and application to Moderate Resolution Imaging Spectroradiometer aerosol retrieval over land, J. Geophys. Res., 112, D13210, doi:10.1029/2006JD007815.

Levy, R. C., L. A. Remer, S. Mattoo, E. F. Vermote, and Y. J. Kaufman (2007b), Second-generation operational algorithm: Retrieval of aerosol properties over land from inversion of Moderate Resolution Imaging Spectroradiometer spectral reflectance, J. Geophys. Res., 112, D13211, doi:10.1029/2006JD007811.

Li, Z., F. Niu, K.-H. Lee, J. Xin, W.-M. Hao, B. Nordgren, Y. Wang, and P. Wang (2007), Validation and understanding of Moderate Resolution Imaging Spectroradiometer aerosol products (C5) using ground-based measurements from the handheld Sun photometer network in China, J. Geophys. Res., 112, D22S07, doi:10.1029/2007JD008479.

Lohmann, U., and J. Feichter (2005), Global indirect aerosol effects: A review, Atmos. Chem. Phys., 5, 715-737.

Longo, K., S. R. Freitas, A. Setzer, E. Prins, P. Artaxo, and M. Andreae (2007), The coupled aerosol and tracer transport model to the Brazilian developments on the regional atmospheric modeling system (CATT-BRAMS): Part 2. Model sensitivity to the biomass burning inventories, Atmos. Chem. Phys. Discuss., 7, 8571-8595.

Misra, A., A. Jayaraman, and D. Ganguly (2008), Validation of MODIS derived aerosol optical depth over western India, J. Geophys. Res., 113, D04203, doi:10.1029/2007JD009075.

Prins, E., J. M. Feltz, W. P. Menzel, and D. E. Ward (1998), An overview of GOES-8 diurnal fire and smoke results for SCAR-B and 1995 fire season in South America, J. Geophys. Res., 103, 31,821-31,835, doi:10.1029/ 98JD01720.

Reid, J. S., P. V. Hobbs, R. J. Ferek, D. R. Blake, J. V. Martins, M. R. Dunlap, and C. Liousse (1998), Physical, chemical, and optical properties of regional hazes dominated by smoke in Brazil, J. Geophys. Res., 103, $32,059-32,080$

Remer, L. A., et al. (2005), The MODIS aerosol algorithm, products and validation, J. Atmos. Sci., 62, 947-973, doi:10.1175/JAS3385.1.

Remer, L. A., D. Tanré, and Y. J. Kaufman (2006), Algorithm for Remote Sensing of Tropospheric Aerosol from MODIS, Algorithm Theor. Basis Doc., ATBD-MOD-02, NASA, Washington, D. C., (Available at http:// modis.gsfc.nasa.gov/data/atbd/index.php).

Satyamurty, P., C. Nobre, and P. Silva Dias (1998), South America, in Meteorology of the Southern Hemisphere, Meteorol. Monogr., 27(49), edited by D. Karoly and D. Vincent, pp. 119-139, Am. Meteorol. Soc., Boston. 
Schafer, J. S., T. F. Eck, B. N. Holben, P. Artaxo, and A. F. Duarte (2008), Characterization of the optical properties of atmospheric aerosols in Amazônia from long-term AERONET monitoring (1993-1995 and 1999-2006), J. Geophys. Res., 113, D04204, doi:10.1029/2007JD009319.

Seinfeld, J. H., and S. N. Pandis (1998), Atmospheric Chemistry and Physics: From Air Pollution to Climate Change, John Wiley, New York.

Setzer, A., and M. Pereira (1991), Amazonia biomass burnings in 1987 and an estimate of their tropospheric emissions, Ambio, 20, 19-22.

Tripathi, S. N., S. Dey, A. Chandel, S. Srivastava, R. P. Singh, and B. N. Holben (2005), Comparison of MODIS and AERONET derived aerosol optical depth over the Ganga Basin, India, Ann. Geophys., 23, 1093-1101.

Twomey, S. (1977), The influence of pollution on the shortwave albedo of clouds, J. Atmos. Sci., 34, 1149-1152, doi:10.1175/1520-0469 (1977)034<1149:TIOPOT>2.0.CO;2.
Walko, R., et al. (2000), Coupled atmosphere-biophysics-hydrology models for environmental modeling, J. Appl. Meteorol., 39(6), 931-944, doi:10.1175/1520-0450(2000)039<0931:CABHMF>2.0.CO;2.

N. M. E. do Rosário, Institute of Astronomy, Geophysics and Atmospheric Science, University of São Paulo, São Paulo, SP 05508-090, Brazil.

H. Elbern, Rhenish Institute for Environmental Research, University of Cologne, Aachener Strasse 209, D-50931 Cologne, Germany.

R. M. Fonseca, S. R. Freitas, and J. J. Hoelzemann, Center for Weather Forecast and Climate Studies, Brazilian National Institute for Space Research, Cachoeira Paulista, SP 12630-000, Brazil.

K. M. Longo, Spatial and Atmospheric Sciences Coordination, Brazilian National Institute for Space Research, São José dos Campos, SP 12630 000, Brazil.

C. Pires, Satellites and Environmental Systems Division, Brazilian National Institute for Space Research, Cachoeira Paulista, SP 12630-000, Brazil. 